\title{
Nutrition in Gynecological Diseases: Current Perspectives
}

\author{
Michał Ciebiera ${ }^{1}$, Sahar Esfandyari ${ }^{2}$, Hiba Siblini $^{3}$, Lillian Prince ${ }^{4}$, Hoda Elkafas ${ }^{2,5}{ }^{\oplus}$, Cezary Wojtyła ${ }^{6}$, \\ Ayman Al-Hendy ${ }^{3}$ and Mohamed Ali $7, *(1)$
}

1 Second Department of Obstetrics and Gynecology, Center of Postgraduate Medical Education, 01-809 Warsaw, Poland; michal.ciebiera@cmkp.edu.pl

2 Department of Surgery, University of Illinois at Chicago, Chicago, IL 60612, USA; sesfan2@uic.edu (S.E.); helkaf2@uic.edu (H.E.)

3 Department of Obstetrics and Gynecology, University of Chicago, Chicago, IL 60637, USA; hsiblini@bsd.uchicago.edu (H.S.); aalhendy@bsd.uchicago.edu (A.A.-H.)

4 Biological Sciences Division, Public Health Sciences, University of Chicago, Chicago, IL 60637, USA; lprince@uchicago.edu

5 Department of Pharmacology and Toxicology, Egyptian Drug Authority (EDA), Cairo 15301, Egypt

6 International Prevention Research Institute-Collaborating Centre, Calisia University, 62-800 Kalisz, Poland; cezary.wojtyla@gmail.com

7 Clinical Pharmacy Department, Faculty of Pharmacy, Ain Shams University, Cairo 11566, Egypt

* Correspondence: mohamed.aboouf@pharma.asu.edu.eg

Citation: Ciebiera, M.; Esfandyari, S.; Siblini, H.; Prince, L.; Elkafas, H.; Wojtyła, C.; Al-Hendy, A.; Ali, M. Nutrition in Gynecological Diseases: Current Perspectives. Nutrients 2021, 13, 1178. https://doi.org/10.3390/ nu13041178

Academic Editor:

Pasquapina Ciarmela

Received: 15 February 2021

Accepted: 30 March 2021

Published: 2 April 2021

Publisher's Note: MDPI stays neutral with regard to jurisdictional claims in published maps and institutional affiliations.

Copyright: (C) 2021 by the authors. Licensee MDPI, Basel, Switzerland. This article is an open access article distributed under the terms and conditions of the Creative Commons Attribution (CC BY) license (https:/ / creativecommons.org/licenses/by/ $4.0 /)$.

\begin{abstract}
Diet and nutrition are fundamental in maintaining the general health of populations, including women's health. Health status can be affected by nutrient deficiency and vice versa. Gene-nutrient interactions are important contributors to health management and disease prevention. Nutrition can alter gene expression, as well as the susceptibility to diseases, including cancer, through several mechanisms. Gynecological diseases in general are diseases involving the female reproductive system and include benign and malignant tumors, infections, and endocrine diseases. Benign diseases such as uterine fibroids and endometriosis are common, with a negative impact on women's quality of life, while malignant tumors are among the most common cause of death in the recent years. In this comprehensive review article, a bibliographic search was performed for retrieving information about nutrients and how their deficiencies can be associated with gynecological diseases, namely polycystic ovary syndrome, infertility, uterine fibroids, endometriosis, dysmenorrhea, and infections, as well as cervical, endometrial, and ovarian cancers. Moreover, we discussed the potential beneficial impact of promising natural compounds and dietary supplements on alleviating these significant diseases.
\end{abstract}

Keywords: nutrition; gynecological diseases; infertility; PCOS; uterine fibroids; endometriosis; microbiome; infection; cervical cancer; endometrial cancer; ovarian cancer; dysmenorrhea; diet; nutrients; complementary and alternative medicine

\section{Introduction}

Gynecological diseases are diseases of the female reproductive organs; these diseases are considered a public health and social problem. These diseases include benign and malignant tumors, infections, and endocrine disorders. All these diseases significantly impact women's quality of life, and many of them, unfortunately, are still lacking efficient treatment plans. Promoting both primary and secondary prevention is essential for the sake of these afflicted women and their reproductive health [1]. Sometimes, applying such preventive approaches is as or even more important than curative procedures. Educating patients about the significance of a healthy lifestyle and explaining hygienic and dietary measures are among these imperative procedures.

Gene-nutrient interactions are central contributors to health management and disease prevention. Nutrigenomics and nutrigenetics are defined as sciences that investigate the relationship between genetic variations and nutrient requirements [2]. Interestingly, it 
was recently reported that nutrients can drive epigenetic changes that can influence such requirements. Nutrition can alter gene expression, as well as the susceptibility to several diseases, including cancer, through genetic and epigenetic changes [3]. During the past decade, it has become clearer that nutrition can exert imprinting effects on the human genome, with many studies indicating that early life nutrition could influence the risk of developing chronic diseases in adulthood $[4,5]$. For example, with regard to the role of nutrition in cancer development, existing evidence suggests that dietary components can impact disease pathogenesis via the activation of tumor suppressor genes, cellular apoptosis, protein translation, and noncoding microRNAs (miRNAs) with roles in messenger RNA (mRNA) stability and translation [6,7]. In this article, we summarized published research in the public domain regarding the existing correlation between nutrients and dietary supplements with common gynecological diseases, highlighting the essential role of nutrients and dietary supplements in halting disease progression.

\section{Infertility}

Infertility is estimated to affect $8-16 \%$ of reproductive-age couples worldwide [8]. Lifestyle and nutritional factors have been shown to be important elements of normal reproductive function $[9,10]$. The literature exploring the relationship between diet and infertility has expanded over the past decade. Studies agree that the intake of folic acid is recommended for the prevention of neural tube defects and has been shown to be related to a lower frequency of infertility and a lower risk of pregnancy loss [11,12]. Further nutritional components or types of diet have been studied in relation to female infertility, including the Mediterranean diet, fats, vitamins, caffeine, smoking, alcohol, and, more recently, probiotics [11].

\subsection{Mediterranean Diet}

The Mediterranean diet is a diet rich in vegetables, fruits, whole grains, legumes, nuts, and olive oil and low in red meat. It has proven to be beneficial in several aspects of human health in general [13] and has also been studied in relation to fertility [14]. Previously, Vujkovic et al. studied the association between a preconception diet and in vitro fertilization (IVF) in a cohort of subfertile couples in the Netherlands and showed that adherence to the Mediterranean diet is associated with a higher chance of pregnancy [15]. A similar effect was later confirmed in a Dutch cohort of couples undergoing first-time in vitro fertilization (IVF), and the authors explained that the high fat content of vegetable oil as part of this diet could be the driving force behind this association. Subsequently, a prospective cohort study of 244 non-obese women who underwent their first IVF in Athens showed that adherence to the Mediterranean diet is associated with an increased chance of clinical pregnancy and live birth [16]. Results from the Nurses' Health Study cohort, which included 438 reported infertilities related to ovulation disorders, showed a significant association between female fertility and consumption of low-glycemic carbohydrates, monounsaturated fatty acids, proteins of plant origin, and supplements with iron, folate, and vitamins [17]. The authors concluded that adherence to such components, which are essentially present in the Mediterranean diet, is associated with a lower risk of ovulatory infertility [17].

\subsection{Fats}

Long-chain omega-3 fatty acids seem to improve female infertility, although it is unclear whether environmental toxins in such food sources, such as fish, can reduce this benefit [18]. In a prospective study of a cohort of 1228 women attempting pregnancy followed for up to six menstrual cycles, the preconception plasma phospholipid fatty acid level was measured at baseline [18]. The authors concluded that monounsaturated fatty acids (MUFAs) are associated with increased fecundability or a shorter time to pregnancy, whereas polyunsaturated fatty acids show the opposite effect. The role of polyunsaturated fatty acids (PUFAs) to decrease fecundability may be due to their effect on androgen synthesis, and androgens have been associated with ovulatory disorders such as polycystic ovary 
syndrome. Fatty acids are also thought to effect fecundability through changes in insulin sensitivity and inflammation, as these pathways also influence ovulatory function [19].

\subsection{Vitamins}

Despite promising evidence from preclinical animal model studies, vitamin D deficiency does not appear to influence human fertility [20,21]. Among women attempting pregnancy in the Nurses' Health Study II (NHSII) cohort, higher intake of vitamin D was not associated with a risk of ovulatory infertility [22]. Similarly, among another large cohorts of women with no history of infertility but with one to two prior pregnancy losses, no association was found between baseline vitamin D levels or vitamin D deficiency and fecundability [23].

A more recent topic of interest is the role of antioxidant consumption based on evidence from experimental association between low antioxidant status and infertility [24]. In one study, increased intake of beta carotene, vitamin $C$, and vitamin $E$ was associated with a shorter time to pregnancy (TTP), but the effects varied with the body mass index (BMI) and age. A shorter TTP was observed among women with a body mass index (BMI) of $<25 \mathrm{~kg} / \mathrm{m}^{2}$ with increasing vitamin C, among women with a BMI of $\geq 25 \mathrm{~kg} / \mathrm{m}^{2}$ with increasing beta carotene, among women aged $<35$ years with increasing beta carotene and vitamin $C$, and among women aged $\geq 35$ years with increasing vitamin $E$ [25].

\subsection{Probiotics}

Considerable attention is lately being given toward probiotics and the effect of the gut microbiome on diseases [26]. Nevertheless, the role of the microbiome in infertility and the role of probiotics in infertility management have not been extensively studied. Lactobacilli are the most studied probiotic bacteria, and they show several mechanisms in protecting the vaginal environment, including production of lactic acid that deters pathogens by lowering the $\mathrm{pH}$ and yielding an acidic environment to the cervico-vaginal mucus [27]; production of bacteriocins, which are antimicrobial peptides and proteins that protect against microbial invasion; and enhancement of immunomodulation by producing $\mathrm{H}_{2} \mathrm{O}_{2}$ and stimulating anti-inflammatory action [28]. In a recent review article, Younis et al. drew attention to the importance of further exploring in future clinical research the role of probiotics in managing infertility [29]. Bhandari et al. demonstrated that Lactobacillis plantarum works to competitively exclude sperm-agglutinating Escherichia coli (E. coli) bacteria. They treated a mice model with E. coli for 10 days intravaginally and then administered L. plantarum to find out that the fertility of this group was comparable to that of the control group, which reinforces the hypothesis that Lactobacillus probiotics may be used as an infertility therapeutic agent [30]. However, further research at the clinical level is needed to confirm these findings.

\section{Polycystic Ovary Syndrome}

Polycystic ovary syndrome (PCOS) is a complex and common hormonal condition in women of reproductive age, characterized by ovulatory dysfunction, chronic anovulation, altered menstruation, and ovarian small cysts on one or both ovaries, which may affect fertility [31]. It is found in approximately $5 \%$ to $10 \%$ of women aged between 18 and 44 years, making it among the most widespread diseases of reproductive-age women. Based on the previous literature, PCOS is associated with other common disorders, such as insulin resistance, obesity, type 2 diabetes, hypertension, endometrial cancer, and hyperandrogenemia. Indeed, most women with PCOS have insulin resistance [32-34].

Although the actual cause of PCOS remains unclear, evidence points to the role of environmental factors, including lifestyle and dietary habits, in the prevention and treatment of PCOS. Therefore, considering these factors may propose new therapeutic strategies for PCOS patients [35,36]. One of the most prominent approaches in treating PCOS is diet therapy for the sake of reducing insulin resistance and reproductive dysfunction. Considering the association of PCOS with obesity and insulin resistance, it should be noted that approx- 
imately a $5 \%$ to $10 \%$ decrease in weight may increase reproductive activity. This might be achieved by weight loss, a decrease in the intake of foods with a high glycemic index and foods rich in fatty acids, and intake of sufficient omega-3, vitamin D, and chromium [35]. There are several studies considering the effects of these nutritional components on the control of PCOS, which we will discuss in this review.

First, foods rich in fat, mainly saturated fatty acids, increase the risk of insulin resistance and its related complications, while diets rich in unsaturated fatty acids decrease the risk of these diseases [35,37]. In this manner, the intake of omega-3 unsaturated fatty acids reduces the risk of PCOS in women with insulin resistance [35]. Moreover, another study indicated that the intake of unsaturated fatty acids affects the levels of pregnanediol 3-glucuronide in cases with PCOS, although the levels of sex hormones do not alter [38].

Current evidence has revealed the role of vitamin D in different metabolic pathways, including the insulin signaling pathway [39]. Previous studies have shown that the vitamin D signaling pathway directly contributes to the activation of the insulin receptor gene [39]. Hence, sub-optimal vitamin D levels may be associated with the pathogenesis of insulin resistance and PCOS [39,40]. In this context, a recent systematic review and meta-analysis demonstrated the association between vitamin $\mathrm{D}$ levels and the metabolic profile, including high-density lipoprotein (HDL-C), fasting blood glucose, and insulin, in PCOS women. Furthermore, vitamin D levels had a positive relationship with sexual hormone binding globulin (SHBG). These findings suggested an important role of vitamin D supplementation in infertile women with PCOS who undergo ovarian stimulation [41].

Recently, attention has shifted toward the effect of vitamin D on ovarian function in PCOS. However, the underlying mechanism of vitamin D on ovarian function is still not fully determined. One possible mechanism is the role of vitamin D in alleviating the inflammatory pathways causing insulin resistance [35]. Previous studies have also indicated the existence of a vitamin D receptor in the granulosa cells of ovaries [42,43]. Moreover, another study showed that the anti-Müllerian hormone (AMH) promoter is under vitamin D down-regulation. AMH is produced by growing follicles, and its excess excretion is linked to PCOS. Therefore, it seems likely that vitamin D supplementation can affect ovarian function and alleviate PCOS [44]. A clinical trial reported that vitamin D supplementation in PCOS women with vitamin D deficiency was related to lower levels of AMH [45]. Consequently, it is tempting to speculate that vitamin D supplementation may be effective in PCOS patients.

Many natural anti-androgen foods have driven scientists' attention to their effects on PCOS therapy. Considering the effect of high insulin levels on the production of testosterone and the high levels of this androgen in PCOS women, improving insulin sensitivity by changing the diet and lifestyle may be regarded as the first-line treatment in this disorder [46,47]. According to previous studies, a low-carbohydrate diet is correlated with a lower risk of metabolic diseases, including insulin resistance, type 2 diabetes, and obesity, along with a lower risk of reproductive disorders [48-50]. However, other studies have shown that a low-carbohydrate diet does not affect the metabolic profile and levels of sex hormones in PCOS women [36,51].

Here, we mention some of the most notable natural anti-androgen foods used in PCOS studies. Soybean comprises isoflavone and phytoestrogens, which are critical in modulating many androgens in the human body [52]. A study showed that soybean phytoestrogen decreased the level of testosterone after three months [53]. Green tea with a high amount of antioxidants was used in a study on PCOS women and promoted insulin sensitivity and lowered the levels of testosterone [54]. Licorice is another phytoestrogen that alleviates the symptoms of PCOS patients and reduces the levels of testosterone [55]. Collectively, natural anti-androgen foods can be considered in the lifestyle to lower testosterone levels and alleviate PCOS.

Flavonoids are polyphenolic compounds of plants that have antioxidant, antiestrogenic, and antidiabetic properties [56]. These natural compounds are emerging as important mediators in the pathogenesis of many reproductive disorders, such as PCOS. Among them, 
quercetin as a bioflavonoid with antioxidant activity is effective in PCOS therapy [57]. It is reported that quercetin may reduce many androgens in rats [58]. Quercetin also reduced insulin resistance in an animal model of PCOS [59].

A clinical trial showed that quercetin improves insulin resistance and hormonal profile in PCOS women [60]. Another study demonstrated that a daily dose of $1000 \mathrm{mg}$ of quercetin for 12 weeks was effective in alleviating PCOS features [61]. Moreover, previous studies have also indicated the potential effects of other flavonoids, such as resveratrol and soy isoflavones, in the treatment of PCOS through the regulation of steroidogenesis, metabolic parameters, ovarian cysts, and follicular development [62-64].

Several studies have suggested the role of minerals in the pathogenesis of PCOS [65]. In this regard, chromium is one of the most important minerals playing a role in carbohydrate and lipid metabolism, whose deficiency is observed in patients with type 2 diabetes. Subsequently, it seems plausible that chromium deficiency increases the risk of insulin resistance [66]. Furthermore, it is evident that PCOS patients have a lower level of chromium, which is associated with insulin resistance [67]. Interestingly, chromium supplementation with a dose of $200 \mu \mathrm{g}$ for three months improved glucose tolerance in PCOS patients. However, it did not change the reproductive function [68]. Another study demonstrated that chromium supplementation with a daily dose of $200 \mu \mathrm{g}$ for eight weeks improved insulin resistance and other metabolic parameters in PCOS women compared to the placebo [69]. It is also reported that chromium picolinate might decrease hirsutism and improve the symptoms of PCOS [70].

Other minerals that participate in reproductive function and are important in the pathogenesis of PCOS are calcium, selenium, zinc, and magnesium [65]. Calcium is a key mineral involved in follicular development and oocyte maturation [71]. It is demonstrated that calcium plays an important role in the insulin signaling pathway. Thus, calcium deficiency may be correlated with insulin resistance and the following PCOS. Obese women with PCOS have lower levels of calcium compared with healthy individuals. Interestingly, vitamin D receptor (VDR) is associated with calcium homeostasis [66,71,72]. A study reported that supplementation of calcium in combination with vitamin $\mathrm{D}$ and metformin $1500 \mathrm{mg}$ for six months decreases the body mass index of PCOS patients. The authors also observed that this supplementation improves follicular development and the fertility rate, although the results were not statistically significant [73].

Selenium is an antioxidant mineral important for the development and activity of reproductive tissues [74]. Lower levels of selenium as well as a higher amount of free radicals have been reported in PCOS patients, which cause a higher production of androgens, luteinizing hormone ( $\mathrm{LH})$, and testosterone [75]. Interestingly, selenium also has insulin-like activities [76]. Therefore, it may affect carbohydrate and lipid metabolism. A clinical trial showed that selenium supplementation at a daily dose of $200 \mu \mathrm{g}$ for eight weeks alleviates insulin resistance in PCOS patients [77]. Hence, selenium supplementation seems to have potential in the adjustment and improvement of insulin resistance and PCOS.

Another mineral, zinc, is a cofactor for many enzymes in carbohydrate and lipid metabolism [78]. Therefore, it also plays a key role in insulin resistance and PCOS. It is reported that women with PCOS represent lower levels of zinc $[79,80]$. Collectively, zinc supplementation may provide an adjunctive nutritional treatment for inducing insulin sensitivity in women with PCOS. Magnesium as a regulator of ATP use is also an important trace element for the metabolism of insulin [81]. A low level of magnesium was observed in women with insulin resistance and high levels of testosterone [82]. It should be noted that only limited studies have investigated the association between magnesium levels and the pathogenesis of PCOS. Hence, their relationship remains unrecognized [65].

\section{Uterine Fibroids}

Uterine fibroids (UFs) are the most common gynecological tumors and a major cause of gynecological morbidity in reproductive-age women $[83,84]$. They are also the leading cause of hysterectomies in the United States, with more than 200,000 hysterectomies 
yearly [85]. The annual costs attributed to UFs range between $\$ 5.9$ and $\$ 34.4$ billion per year in the United States alone and hundreds of billions worldwide [86]. Although UFs are benign tumors, they can cause a myriad of symptoms and outcomes, including pelvic pain, abnormal uterine bleeding, bladder dysfunction, and even infertility [87]. Despite the high morbidity and cost associated with UFs, the exact pathophysiology is not completely delineated [88], yet there are theories and reports of associated risk factors. Some of these risk factors include an increased body mass index, early age at menarche, nulliparity, vitamin D deficiency, and African American ethnicity [89]. A growing body of research has shed light on increasing evidence that dietary factors may play a role in UF etiology and growth [90]. This is hypothesized to be due to their ability to modify endogenous hormones as well as their inflammatory or anti-inflammatory effects.

\subsection{Fats}

Fats have been extensively studied in relation to UFs, seeing their effect on the inflammatory milieu. For example, trans fats are reported to influence levels of interleukin 6 (IL-6) and other inflammatory markers [91]. Fats also have an effect on hormone levels, as a meta-analysis of 13 intervention studies reported that reducing fat consumption results in lower serum estradiol levels [92].

As previously mentioned, the African American race is considered a risk factor for UFs, and the time of onset is estimated to be 10 to 15 years earlier for this race cohort [93]. In addition, the source of dietary fat intake is shown to be generally different between black and white women in the United States, with black women consuming more fat from meat and fish and less from dairy products as compared to white women [94]. The Black Women's Healthy Study (BWHS) [95] was the first prospective study comprising solely a black women cohort to study the association between dietary fat and UF risk. More than 12,000 African American women were followed for eight years, with 2695 having fibroids that were self-reported, ultrasound detected, or detected during hysterectomy or other surgery. Wise et al. studied data from the BWHS and reported an increased risk of fibroids with the intake of specific $\omega-3$ polyunsaturated fatty acids (PUFAs) but no consistent association with total fat or other fat subtypes, with the exception of total monounsaturated fatty acid (MUFA) intake, for which a positive association was identified [96]. Nevertheless, fish consumption was the main source of PUFAs in this population, so results may have been confounded by environmental contaminants in fish intake. Biomarker measurements of exposure to pollutants in future studies could help differentiate the extent to which the association is explained by pollutants or fatty acids themselves.

Moreover, the BWHS did not measure circulating fatty acids (FAs) that reflect dietary intake and FA metabolism and reflect the internal dose more precisely than estimations based on diet assessment questionnaires, and UF case identification has been based on self-reporting. To expand on the literature, Wise et al. studied this association in the Study of Environment, Lifestyle, and Fibroids (SELF), in which a prospective cohort of African American women underwent serial ultrasound screening for UF incidence during a five-year period [97]. Findings were consistent with those from the BWHS, in which higher intake of marine $\omega-3$ PUFAs are associated with a 13-21\% increased risk of UFs.

A more recent prospective study done by Harris et al. examined a cohort aged 25-42 in the NHS II and studied the erythrocyte membrane FA levels of a subset of women [98]. This allowed considering dietary intake and endogenous synthesis and transformation of FAs instead of serum FA levels alone, since erythrocytes reflect long-term intake better than plasma. This study showed an inverse association between total $\omega-3$ PUFAs and a positive association of trans FAs and the onset of uterine fibroids. Moreover, it has been shown that there is an estrogenic or inflammatory effect of dietary fat reflected by the reduction in women's quality of life [92] and by an increase in T helper cytokines associated with fat intake, which is hypothesized to promote chronic inflammation and fibroid tissue growth [99]. However, total trans FAs were associated with higher odds of fibroids. In contrast, an Italian case-control study of 843 histologically confirmed UF cases 
and 1557 controls reported no association between butter, margarine, or oil intake during the year prior to the study and fibroid risk [100]. Also consistent with these null results was a cross-sectional study of Japanese women including 54 UF cases and 234 controls that reported no association between all fat subtypes and fibroid risk [101]. Islam et al. stated that the myometrium has a higher amount of arachidonic acid than UFs, with alphalinolenic acid (ALA) being higher in UFs. Treatment with eicosapentaenoic acid (EPA) and docosahexaenoic acid (DHA) reduced the monounsaturated fatty acid content in UFs and controls. However, these did not reflect changes in the mRNA expression of extracellular matrix (ECM) components. Omega-3 fatty acids reduced the levels of sterol regulatory molecules (e.g., ATP-binding cassette sub-family G member 1 (ABCG1) or ATP-binding cassette transporter member 1 (ABCA1)) in both cell types. It also reduced a cytochrome 450 family member CYP11A1, the mitochondrial enzyme that catalyzes the conversion of cholesterol to pregnenolone. The authors concluded that omega- 3 fatty acids modulate the lipid profile, mechanical signaling, and cellular lipid accumulation in UFs [102].

\subsection{Vegetables, Meat, and Phytochemicals}

National surveys have shown that African Americans have a lower intake of vegetables and fruits $[103,104]$. Several studies have demonstrated that diets rich in vegetables, fruits, and dairy foods play a positive and sometimes protective role in UFs [105] and, conversely, that substantial intake of red meat might increase the risk of fibroids. Fruits and vegetables are good sources of vitamins, antioxidants, and phytochemicals, and numerous studies have shown that they may decease fibroid risk. Wise et al. evaluated the association between fruit and vegetable intake and UF risk in the BWHS [105]. They studied specific components such as carotenoids, folate, fiber, and vitamins A, C, and E. Results suggested that fruit intake is inversely associated with UF risk, with the highest reduction observed for citrus fruit intake. It has been hypothesized that citrus fruit may reduce UF risk through pathways mediated by sex hormones or by inhibition of sex hormones receptors.

In a case-control study in China, He and co-authors confirmed the reduced UF risk with fruits and vegetables but found no association with meat intake [106]. The authors hypothesized that the protective role of a high intake of vegetables and fruits may be related to fibers and lycopene. Fibers can influence sex hormone and bile acid metabolism by interrupting the enterohepatic circulation. Lycopene, which makes up the red pigment in tomatoes, has been proven to decrease fibroid size in a Japanese quail study, but these results are yet to be proven in humans [107]. Phytoestrogens, which are bioactive nutrients found in plants such as soy, have been found to have moderate estrogen and antiestrogen activity [108]. Because of the presence of the phenol ring, soy isoflavone, a type of phytoestrogen, can bind to the estrogen receptor and compete with estradiol. Recently, an in vitro study explored the effects of quercetin and indole-3-carbinol (I3C) on ECM expression, cell migration, and proliferation in human myometrial and UF cells [109]. Quercetin is a flavonoid with known antifibrotic effects found in most edible fruits and vegetables, such as tea, lemon, tomato, onion leaves, and strawberry, while I3C is a naturally occurring glucosinolate in cruciferous vegetables. Results showed that both treatments significantly reduce the expression of ECM markers collagen type I and fibronectin but not versican. Moreover, the treatments inhibited UF cell migration [109].

Anthocyanins are water-soluble flavonoid pigments that are abundant in blueberries, raspberries, and strawberries [110]. Strawberries have anti-inflammatory, anti-oxidative, anti-proliferative, and genomic-protective effects [111,112]. Islam et al. explored the effect of different strawberry Alba cultivar extracts on apoptosis, fibrosis, and oxidation in the myometrium and UF cells. Results showed that anthocyanin-rich strawberries induce apoptosis but suppress glycolysis and fibrosis in UF cells. Following strawberry treatment, the authors observed an increase in reactive oxygen species levels in UFs. Additionally, the anthocyanin-rich extract significantly reduced fibronectin, collagen, and versican mRNA expression in UF cells [113]. In addition, a recent study tested five different strawberry cultivars to identify the one with the best anti-UF effects. The authors found that Alba 
and Romina cultivars presented the best results: they decreased collagen $1 \mathrm{~A} 1$, fibronectin, versican, and activin A mRNA expression in UF cells [112]. In vitro studies have shown that curcumin, which is abundantly found in turmeric, prevents fibroid growth as it inhibits UF cell proliferation by regulating the apoptotic pathway [87]. Isoliquiritigenin, which is abundantly found in liquorice, and soybean have been reported to induce growth inhibition and apoptosis of UF cells [114]. On the other hand, studies have also shown both stimulatory and inhibitory effects of genistein, which is abundantly found in soybeans and fava beans, on fibroid cell proliferation $[115,116]$. Lower concentrations $(\leq 1 \mu \mathrm{g} / \mathrm{mL})$ stimulated proliferation, whereas higher concentrations $(\geq 10 \mu \mathrm{g} / \mathrm{mL})$ significantly inhibited proliferation, decreased proliferating cell nuclear antigen (PCNA), and increased apoptosis of both myometrial and leiomyoma cells. Finally, resveratrol, found in mulberries, peanuts, and grapes, is shown to be inversely associated with the proliferation of fibroids also via inducing apoptosis of UF cells in vitro [87].

$\mathrm{Al}$ Hendy et al. showed that intake of epigallocatechin gallate (EGCG), a green tea extract, reduces fibroid size [87]. Thirty-nine reproductive-age women with symptomatic UFs were studied, and although the placebo group was found to have an increase in fibroid size, those randomized to the green tea extract treatment showed an average of $32.6 \%$ $(p=0.0001)$ reduction in UF volume. This was attributed to EGCG's inhibitory effect on the proliferation of leiomyoma cells and induction of apoptosis, as was proven by Al Hendy et al. preclinically.

\subsection{Dairy Foods and Vitamins}

National surveys have shown that African Americans consume less dairy food than white Americans do, and they are less likely to take vitamin supplements as well [117]. Dairy foods have antitumorigenic constituents, including calcium, vitamin D, butyric acid, and milk proteins [118]. Yet, milk may contain estrogen and progesterone that may increase the risk of hormone-dependent tumors [119]. In the BWHS cohort, Wise et al. prospectively studied the effect of dairy food on UF risk and found that women who had four of more dairy servings per day had a 30\% reduction in the incidence of fibroids [120]. Calcium, phosphorus, and the calcium-to-phosphorus ratio (as an indicator of calcium bioavailability) were inversely associated with UF risk. It is hypothesized that calcium may reduce fat-induced cell proliferation. In this study, Wise et al. did not find an effect of dietary vitamin $\mathrm{D}$, and this was attributed to the fact that the largest bioavailable sources of vitamin $\mathrm{D}$ are derived from sun exposure and supplements. In a later study, Wise identified single-nucleotide polymorphisms in genes involved in vitamin D metabolism that were significantly associated with UFs [121]. It has also been shown African American women have lower serum vitamin D levels than white Americans, which could explain the increased risk of UFs [122]. Al Hendy et al. observed that vitamin D could be a potent antiestrogenic agent that reduces the expression of sex steroid receptors and consequently the risk of UFs [123]. Vitamin D has been shown to be a potent antitumor agent inhibiting UF cell proliferation and decreasing UF size in in vivo animal models as well as several clinical trials $[122,124,125]$. Mechanistically, vitamin D might exert its anti-UF effects via induction of DNA repair genes and amelioration of DNA damage both in UF cells and in myometrial cells at risk of developing UFs [126-128]. More recently, Sheng et al. published a protocol for the first open-label randomized controlled trial to evaluate whether supplementation with vitamin D can reduce the risk of UFs in reproductive-age women, and future results of this study could provide new evidence of the benefit of vitamin D intake [129].

\subsection{Pollutants and Metaloestrogens}

As explained previously, fibroid development is mostly mediated by estrogen and progesterone receptors. Many pollutants resemble these steroid hormones and affect these receptors as endocrine-disrupting chemicals (EDCs). As described in a recent review, these include phthalates, parabens, environmental phenols, alternate plasticizers, diethylstilbestrol, organophosphate esters, and tributyltin. The US National Institute of 
Environmental Health Sciences (NIEHS) defines EDCs as "chemicals that interfere with the body's endocrine system and produce adverse developmental, reproductive, neurological and immune effects." EDCs have been described to bind to nuclear receptors, such as estrogen receptors, and alter hormone functions by mimicking endogenous hormones and/or blocking them from interacting with their receptors. EDCs may also induce genomic and nongenomic signaling. For example, bisphenol A and diethylstilbesterol have been shown to activate nongenomic signaling through estrogen receptors [130]. Epidemiologic studies have shown that exposure to certain EDCs is associated with increased fibroid risk and severity [131].

Some heavy metals, which are mostly present in tobacco smoke, polluted air, seafood, and leafy green vegetables, are also associated with increased fibroid risk. The Endometriosis: Natural History, Diagnosis, and Outcomes (ENDO) study demonstrated a direct link between fibroids and increased serum levels of cadmium and lead and urinary cobalt levels [132]. Heavy metals as metaloestrogens activate the estrogen receptor in the absence of estradiol and affect the hypothalamic-pituitary-ovarian axis as do endocrinedisrupting compounds [133].

\section{Endometriosis}

Endometriosis is an inflammatory and estrogen-dependent gynecological disorder characterized by the proliferation of endometrial cells outside the uterine cavity [134]. Indeed, endometrial cells migrate from their original site, the uterus, to other organs and produce endometrial-like tissues in various anatomical sites outside the uterine cavity, particularly the ovaries and the peritoneum $[134,135]$. Although the symptoms of endometriosis are not specific and most of them are similar to symptoms of other gynecological diseases, it may cause pelvic pain and infertility. Exosomes act as biomarkers for female reproductive disease diagnosis and therapy [136]. Moreover, it should be noted that endometriosis creates a significant burden in terms of health expenditure and quality of life all over the world [136]. It is a disorder with approximately 3 to 11 years of diagnostic delay, resulting in the dysfunction of the reproductive cycle in reproductive-age women. The exact prevalence of endometriosis is not determined due to a lack of proper non-invasive diagnostic techniques, but it is estimated that about $10 \%$ of women of reproductive age suffer from endometriosis. Furthermore, its prevalence rises to approximately $20 \%$ to $50 \%$ in women with pelvic pain or infertility [136-138].

Endometriosis is a multifactorial disorder that involves genetic and immunologic pathways, contraction of the smooth muscle, and inflammation, as well as environmental factors, including dietary habits and nutrition components. According to previous studies, the development of endometriosis requires alterations in several biological pathways for disease establishment $[139,140]$. The present work aimed to summarize the biological effects of nutrition components, including omega-3, omega-6, vitamin D, N-acetylcysteine, flavonoids, and L-carnitine, on the prevention and treatment of endometriosis.

Foods rich in omega- 6 fatty acids, such as red meat, are correlated with higher levels of estradiol and estrone sulfate, which is linked to higher concentrations of steroids, inflammation, and the development of endometriosis [141]. Instead, supplementation with omega-3 may decrease the growth of endometrial implants and the production of inflammatory factors, particularly in patients with stage III or IV endometriosis [142].

Vitamin D is a classic regulator of inflammatory pathways and has been widely studied in the field of endometriosis. Macrophages, lymphocytes, and dendritic cells (DCs) express enzymes that use this vitamin [143]. It has been shown that these cells express CYP27B1, while DCs also express CYP2R1, which are both key enzymes in vitamin D metabolism. All these cell types can convert hydroxy vitamin D3 (25(OH)D3) into bioactive dihydroxy vitamin D3 $(1,25(\mathrm{OH}) 2 \mathrm{D} 3)$, enabling them to respond not only to the active vitamin D metabolite but also to its precursors]. Vitamin D boosts the shift away from Th1-type responses to a Th2-type immunity by repressing the secretion of IL-12, IL-2, tumor necrosis factor (TNF), and $\gamma$-interferon by macrophages, T cells, and DCs [143]. Therefore, the 
active form of vitamin D may act in the endometriosis lesion by lowering the production of prostaglandins and inflammatory cytokines [143]. A clinical trial demonstrated that patients with dysmenorrhea treated with a dose of 300,000 IU of vitamin D had lower pain along with lower use of nonsteroidal anti-inflammatory drugs (NSAIDs) [144]. However, another clinical trial reported that vitamin D supplementation at a dose of 50,000 IU weekly for 12 weeks did not affect endometriosis-related pain [145]. Hence, further studies are required in this area of research.

$\mathrm{N}$-acetylcysteine, also known as acetylcysteine, can effectively reduce inflammation and alleviate endometriosis. Interestingly, foods with $\mathrm{N}$-acetylcysteine, including onions, garlic, wheat germ, broccoli, and Brussels sprouts, are reported to have the ability to control cell proliferation and oxidative stress in endometriotic cells [146]. A study observed that the size of the endometrioma in patients supplemented with $\mathrm{N}$-acetylcysteine at a dose of $1800 \mathrm{mg}$ reduced significantly [147].

Studies have shown that quercetin acts as a natural flavonoid in endometriosis therapy [148]. A study reported that quercetin affected the hypothalamic-pituitary-gonadal (HPGA) axis in an animal model of endometriosis. Therefore, quercetin decreased the levels of Luteinizing hormone (LH) and follicle-stimulating hormone (FSH). Furthermore, it reduced the levels of estrogen and progesterone receptors [149]. Resveratrol is a polyphenol ingredient found in grapes, peanuts, and cocoa with anti-inflammatory and antioxidant activities. A study reported that resveratrol supplementation reduced the size of endometriomas in an animal model. Moreover, it reduced the levels of vascular endothelial growth factor (VEGF) in endometrial tissue, which is efficient for endometriosis therapy [150]. A randomized exploratory trial in infertile patients with endometriosis (stage III-IV) within the window of implantation revealed that receiving resveratrol (400 $\mathrm{mg}$ ) for 12-14 weeks significantly attenuated the levels of VEGF and TNF- $\alpha$ genes and protein in the ectopic endometrium compared with the placebo group [151]. Several studies have reported that sulforaphane (SFN), an isothiocyanate in cruciferous vegetables such as cauliflower, cabbage, and broccoli, has antioxidative, antitumor, anti-inflammatory, and immune-enhancing effects [152,153]. Zhou et al. reported that administrating SFN in an endometriosis rat model for three weeks dose-dependently attenuated the volumes of the adhesion score and endometriotic foci. Further, post-treatment of SFN repressed levels of VEGF, interferon gamma (IFN- $\gamma$ ), TNF- $\alpha$, IL- 6 and IL-10 in plasma and peritoneal fluid and regulated the expression of cleaved caspase-3, bcl-2, Bax, and VEGF in endometrial tissue by repression of the PI3K/Akt pathway [152]. These studies suggest that flavonoids may inhibit ectopic endometrium growth.

L-carnitine is an amino acid analogue involved in fatty acid oxidation and energy metabolism [154]. Studies have shown that L-carnitine supplementation acts as a doubleedged sword in the progression of endometriosis. For instance, it was reported that L-carnitine intensified an already presented endometriotic lesion when cells expressed estrogen receptors, while it improved this situation when cells did not express estrogen receptors. Clearly, the underlying mechanism is linked to the cellular features of cells arising from the endometrium [155].

Altogether, there are many studies on the role of different nutrients in endometriosis, which provide promising approaches to disease control. It seems that foods rich in omega-3, $\mathrm{N}$-acetylcysteine, and polyphenol, in addition to decreased consumption of omega- 6 fatty acids, may lower the plausible risk of endometriosis. Therefore, dietary education appears to be a promising strategy for the control of the disease.

\section{Vaginal Microbiome, Nutrients, and Female Reproductive Tract Infections}

The worldwide burden of reproductive tract infections (RTIs) is a vast and major public health concern, particularly in developing countries where RTIs are widespread [156]. RTIs, except for human immunodeficiency virus (HIV), are considered the next major cause of disease burden (after maternity-related causes) in young women in developing countries. RTIs involve three sets of infections [156,157]: sexually transmitted infections 
(STIs), infections that arise from the overgrowth of organisms usually present in the reproductive tract, and, finally, infections connected with therapeutic plans, including abortion and insertion of intrauterine devices.

Female RTIs usually start in the lower genital tract as vaginitis or cervicitis and may exhibit irregular vaginal discharge, genital discomfort, itching, and burning sensation with urination. RTIs causes a heavy burden on women if untreated, and they can cause serious infertility, cervical cancer, ectopic pregnancy, menstrual disturbances, pregnancy wastage, and low-birth-weight babies [158].

An environment's microbiota consists of resident bacteria, viruses, fungi, protists, and archaea. Either culture-based or sequence-based techniques can distinguish the bacterial microbiome. Both methods have been used to define various sites within the women's reproductive tract, including the vagina, cervix, and uterus. While sequence-based techniques are not routinely used to recognize bacteria in the female reproductive tract, this is an emerging research interest field. Bacterial infections of the female reproductive tract, including vaginitis, cervicitis, and endometritis, have been described [159], as this pathogenic environment may cause inflammation and immune activation in the endometrium, impairing embryo implantation and the onset of a successful pregnancy $[159,160]$.

The interplay between nutrition and infectious diseases has been identified. In the era before antibiotics, the diet was a vital part of controlling infections [161]. Malnutrition, including undernutrition and overnutrition, can increase sensitivity to infectious diseases and magnify the infection severity, which can worsen by malnutrition; the gut microbiota has been attracting interest as an essential mediator in the complex relationships linking food, the human body, and infectious diseases [162].

An optimal vaginal microbiota is controlled by Lactobacillus species, which produce the metabolite lactic acid. Lactic acid decreases the $\mathrm{pH}$ of the vaginal microenvironment [163] and, throughout immunomodulatory and direct inhibitory effects, may defend against the acquisition of STIs, including Chlamydia trachomatis (CT) and HIV [164,165]. Women with a non-optimal microbiota, as epitomized by the clinical condition of bacterial vaginosis (BV), have vaginal microbial communities low in Lactobacillus spp. and are instead colonized by a variety of anaerobes that generally produce little or no lactic acid. Some of these bacteria produce metabolites such as biogenic amines and short-chain fatty acids that may be pro-inflammatory and linked with symptoms such as vaginal malodor and discomfort. These metabolites may also increase susceptibility to STIs. Moreover, women with a low-Lactobacillus non-optimal vaginal microbiota have an increased risk of being infected with STIs and ascending infection, including pelvic inflammatory disease (PID) and increased risk of preterm birth (PTB) [166].

Bacterial vaginosis (BV) is the most common reason for vaginal complaints amongst reproductive-age women. The prevalence of BV in infertile women is high (19\%), and an abnormal microflora occurs in 39\% of infertile patients [167,168]. BV is a clinical case marked by a transformation from a Lactobacillus-dominant bacterial community to higher diversity and a greater abundance of anaerobes and a subsequent rise in vaginal $\mathrm{pH}(>4.5)[169,170]$.

BV is considered a risk factor for several common sexual transmitted infections [171], including those induced by the bacteria Neisseria gonorrhea, CT, and Mycoplasma genitalium; the protozoan Trichomonas vaginalis; and viruses such as HIV, human papillomavirus (HPV), and herpes simplex virus type 2 (HSV-2) [158,169,170]. Many data have reported the relationship between diet and nutritional status in BV, but the mechanism is still unclear [162,172]. Many studies have found associations between BV and low micronutrient status, including vitamins $\mathrm{A}, \mathrm{C}, \mathrm{E}$, and $\mathrm{D}$ and $\beta$-carotene, and low dietary intake of folate and calcium $[162,170,172-174]$.

\subsection{Bacterial Vaginosis and Vitamin D Deficiency}

Many records describe higher frequencies of BV among women with low vitamin D concentrations (often marked as $<20 \mathrm{nmol} / \mathrm{L}$ or $<30 \mathrm{nmol} / \mathrm{L}$ ) [175,176]. In addition, vitamin 
D supplementation is effective in eliminating BV [177]. Race/ethnicity has significant population-level impacts on vitamin D status, BV status, and pregnancy outcomes. Women of African heritage are also doubly as likely to receive a clinical diagnosis of $\mathrm{BV}$, and analyses of the vaginal microbiota reveal that it is more likely to be colonized by specific BV-associated bacteria.

\subsection{Role of a High-Fat Diet and a High-Sugar-Diet on Altering the Vaginal Microbiome}

In specific subsets of women, a correlation between a high-saturated-fat diet, a higher glycemic load, and lower nutritional density with BV has been found, in addition to a contrary relationship between BV and higher folate, vitamin E, and calcium consumption $[170,172,178]$. BV has also been epidemiologically combined with obesity [169]. Subsequently, shifts in the vaginal microbiota balance due to infection with BV alters the composition referred to as polybacterial dysbiosis and to disease such as vaginal HPV [179]. In addition, BV has been associated with acquiring and transmitting HIV and other sexually transmitted pathogens $[180,181]$.

Lactobacillus dominance is that the high starch content of human diets leads to high glycogen levels in the vaginal tract, creating a suitable Lactobacillus environment. Lactobacilli and other fermentative bacteria and vaginal epithelial cells produce lactic acid and are responsible for acidifying the vaginal microenvironment $\mathrm{pH}$ to $<4.5$, which gives the vaginal microbiota a certain level of balance and ability to withstand some infections. This microbiota is shown by a low degree of diversity and the high dynamics of its structure changes under the control of various exogenous and endogenous factors. Nutrients play an important role in altering the vaginal microbiome diversity. A diet deficient in vitamin A, C, D, and E, calcium, folate, and beta-carotene but rich in fats and sugar, causes vaginal infections such as $\mathrm{BV}$, which are linked to preterm birth, increased risk of HIV transmission, increased risk of HPV infection, and cervical, endometrial, and ovarian cancers (Figure 1).

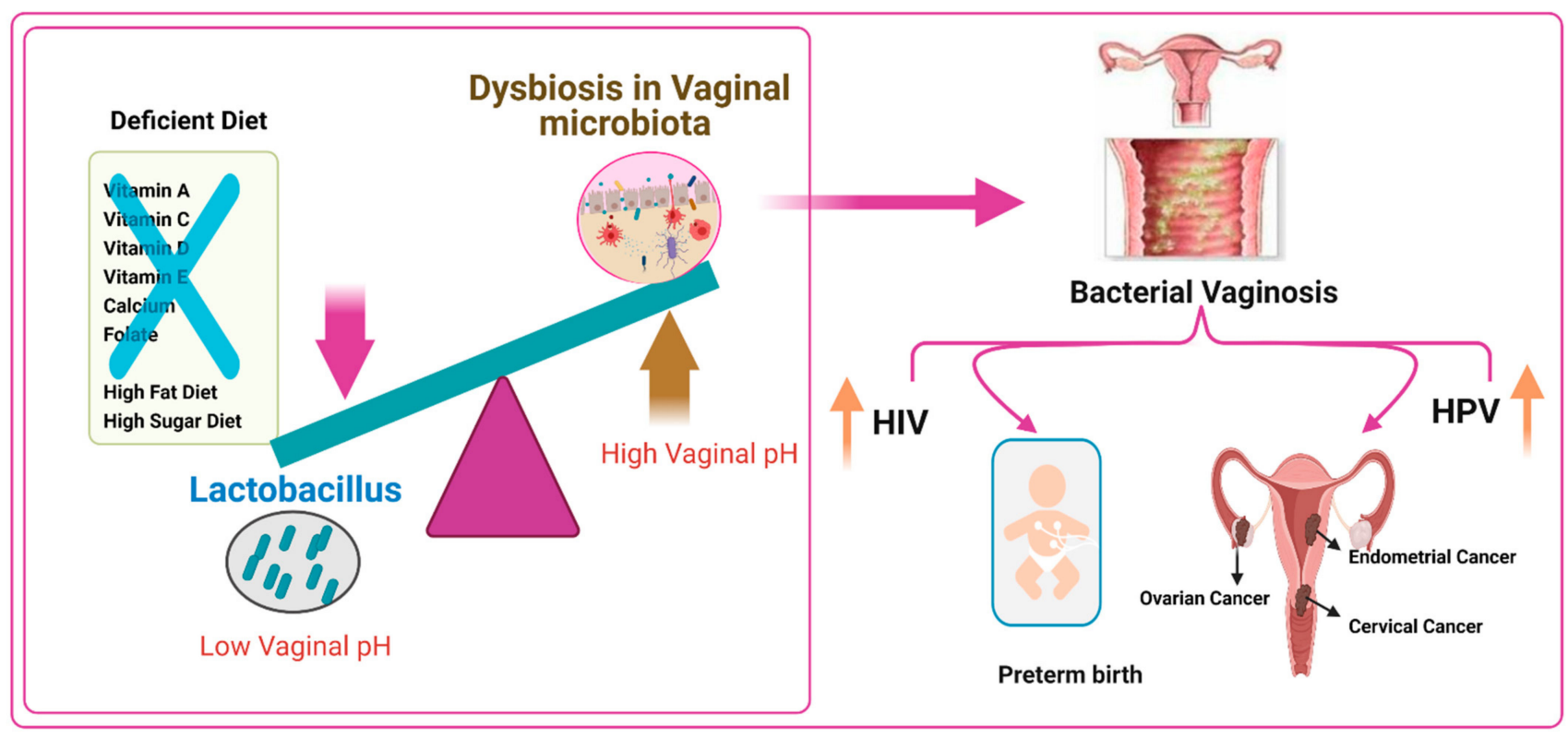

Figure 1. Impact of diet on the vaginal microbiome. A diet deficient in vitamins A, C, D, and E, calcium, folate, and beta-carotene but loaded with fats and sugar leads to altering the vaginal microbiota and increase susceptibility to infections causing bacterial vaginosis, which are associated with preterm birth, raising the risk of human immunodeficiency virus (HIV) transmission, human papillomavirus (HPV) infection, and cervical, endometrial, and ovarian cancers. 


\section{Gynecological Cancers}

Neoplastic diseases are a growing public health problem, considering their incidence and subsequent health care burden [182,183]. Interdisciplinary oncological care is extremely important for the sake of successful cancer cure. Adequate prophylaxis, diagnostic workup, and therapeutic plan are essential in order to either achieve a curative goal in the case of curable diseases or prolong patient survival and quality of life in the case of an incurable disease. In gynecological oncology, the utility of prophylaxis and healthpromoting behavior strategies can result in three outcomes: effective, leading to poor effects, or ineffective. Examples of the first outcome are vaccination and the application of effective screening tools in cervical cancer, with subsequent reduced morbidity and mortality [184]. Intermediate effective outcomes are achieved in endometrial cancer, where behaviors such as avoiding aggravating factors and following their effective treatment in co-morbid conditions (diabetes, hypertension, and obesity) reduced morbidity in some groups [185]. Unfortunately, following the same measures in the case of ovarian cancer resulted in practically ineffective outcomes [186].

Diet and nutritional intervention plans in oncology should be individualized and focused on adjusting nutrient needs for cancer patients [187]. The literature estimates that diet and nutritional compounds may contribute to approximately $20-60 \%$ of cancers worldwide [188]. Collectively, more investment should be made in research detailing the role diet/nutrition plays both in the occurrence of cancer and in its cure, such as tolerance to radiation and chemotherapy. The current literature relatively ignores this important angle, while focusing on exploring new chemotherapeutics, immunological therapies, and new operative techniques, including those only for women [189]. Recent findings have shown that neither fruits nor vegetables might be convincingly or possibly associated with the risk of any cancer. Moreover, vitamins and mineral compounds do not reduce cancer risk in populations that are well nourished. Therefore, they should not be used for standard cancer prevention. However, specific components of certain fruits and vegetables might present protective properties [189]. Seemingly, even if studies in this area are scarce, it is worth collecting at least some available data to draw conclusions for future research.

\subsection{Cervical Cancer}

Cervical cancer has been studied for many years. Unlike other cancers, cervical cancer is caused by sexually transmitted infections (STIs) with certain types of HPV. A persistent viral infection in high-risk groups was recognized as necessary for the development, maintenance, and progression of cervical intraepithelial neoplasia (CIN) and cervical cancer [190]. Some environmental and lifestyle co-factors were found to influence such disease progression, including inappropriate diet, cigarette smoking, coexistence of STIs, combined oral contraceptive (COC) use, high parity, low socioeconomic status, early sexual activity, or multiple sexual partners.

Available studies have demonstrated that reactive oxygen species (ROS), either independently or orchestrated with HPV, may play a role in cervical cancer pathogenesis. Therefore, consumption of dietary antioxidants, such as carotenes, ascorbic acid, and vitamin D, might offer a protective role via neutralizing such harmful ROS [188]. Moreover, antioxidants may modulate the immune system in favor of a better response to the cancer microenvironment [191].

Likewise, natural antioxidants may slow down or protect against persistent HPV infection and thus later cervical cancer development [192,193]. For example, Tomita et al. highlighted an existing correlation between both low intake of fruits and vegetables and smoking habits with an increasing risk of developing high-grade CIN [192]. In addition, in 2012, Jia et al. published data suggesting that eating higher amounts of fresh vegetables and drinking green tea may reduce the overall risk of cervical cancer [194]. Interestingly, vitamins such as $C$ and $E$ can serve as efficient antioxidants, with studies linking higher serum antioxidant vitamin levels with a lower risk of cervical cancer, especially in passive smokers [195]. It was also demonstrated that the dietary intake of carotenoids or retinols, 
lutein, different xanthines, and ascorbic acid was associated with a reduced incidence of HPV persistence in infected women [196]. Furthermore, low serum levels of lycopene, retinol, and tocopherols are suspected to increase the risk of high-grade CIN, while higher serum levels of carotenoids and gamma tocopherol could even reduce the overall risk of this kind of dysplasia [192].

A summarized review by Ono et al. in 2020 concluded that various nutritional antioxidants may affect HPV infection-derived cervical diseases. They suggested that the intake of vitamin A, carotenoids, and vitamin D may inhibit cervical cancer development at early stages. Conversely, the intake of vitamin $C$ and $E$ may be useful in the inhibition of the cervical cancer development process [197], while vitamin A's main effect is inhibition of HPV infection and CIN development [188]. In 2000, Yeo. et al. found that women with low serum retinol levels were at an increased risk of low-degree CIN compared with women who had higher levels of retinol [198]. Interestingly, Huang et al. (2020) found that the dietary intake of vitamin A, equal to or higher than $1448.155 \mathrm{mcg}$, increased the risk of HPV infection by 70\% [199]. Vitamin E is a group of fat-soluble compounds including tocopherols and tocotrienols with antioxidant effects protecting cell membranes from ROS [200]. Studies have confirmed the same findings that high circulating levels or a greater intake of vitamin E might reduce the risk of CIN or cervical cancer [201]. Concerning other nutrients such as vitamin $\mathrm{D}$ and folic acid, a recent randomized controlled trial by Vahedpoor et al. (2017) performed in 58 women diagnosed with low-grade CIN revealed that after six months of vitamin D administration, the regression of lesions was observed more commonly in women who consumed vitamin D compared with controls [202]. Folic acid has not been extensively studied recently, and the available data are relatively old. Hernandez et al. (2003) reported that the total folate serum level presented an inverse, dose-responsive correlation with low-grade cervical squamous intraepithelial lesions and high-grade squamous intraepithelial lesions [203].

Natural compounds with chemopreventive/chemotherapeutic potential and antioxidant features have received increased attention in the past few years. Some natural compounds extracted from plants, such as curcumin and EGCG, have been found to exhibit anticancer properties, e.g., increasing tumor cell sensitization to different forms of therapy [204,205]. Seemingly, curcumin requires special attention. This compound (also known as diferuloylmethane) is present in the turmeric rhizome and shows different anti-inflammatory and antioxidant properties [205]. Briefly, curcumin contributes to the inhibition of nuclear factor kappa B-regulated gene factors that control apoptosis, proliferation, invasion, or angiogenesis, in addition to inhibition of nuclear factor kappa $B$ activation through the modulation of different kinases [205], which contributes to the resistance of human cervical cancer cells and results in increased cell death [206]. EGCG is another interesting compound with anticancer properties. It is a polyphenol with proven antiproliferative, antiangiogenic, antimetastatic, and proapoptotic properties in several tumor models [207]. EGCG is a potent inhibitor of several kinases as well as the mammalian target of rapamycin (mTOR) signaling, besides acting as a modulator in inflammatory processes [208]. EGCG modulates ROS production, which might be linked to its antitumorigenic effects. The EGCG-derived modulation/inhibition of nuclear factor kappa B signaling is responsible for its effect against angiogenesis, cell movement, and viability [208]. Finally, resveratrol, which is a phytoalexin found in fruits like grapes, blueberries, or peanuts, exhibits anticancer effects via interacting with several important molecules involved in tumor development, such as activators, kinases, or nuclear factor kappa B. Moreover, resveratrol shows antiproliferative effects on cervical cancer cell lines through cell cycle modulation with accumulation of the cells in the S phase [204].

To conclude, several nutrients with antioxidant effects may present potent abilities to intervene in the natural history of cervical cancer tumorigenesis connected with HPV infection [197]. Selected vitamins (such as vitamins A and D) and natural compounds (e.g., EGCG) demonstrate a positive effect in halting the cervical cancer disease process. 
Obviously, the available data are inconclusive, and their quality may be undermined. Therefore, more well-designed, large randomized clinical studies are needed.

\subsection{Endometrial Cancer}

Endometrial cancer (EC) is currently one of the most common malignant neoplasms affecting women worldwide. Unfortunately, the direct underlying etiology has not been clearly described and understood. EC is known to occur mainly in postmenopausal women [209]. Contributing risk factors are older age, nulliparity, diabetes, estrogenonly hormone replacement therapy, and obesity [210]. Fortunately, the survival rate ranges from about $75 \%$ to $90 \%$ in patients diagnosed at early stages [211]. Differences in histological patterns and clinical outcomes divide EC into two types. Type I cancers present as endometrioid adenocarcinomas, and this kind of tumor is often preceded by endometrial hyperplasia. Importantly, the development of this kind of tumor is mostly influenced by the long-lasting stimulation of estrogens on the endometrium [210,212]. Type II tumors are mostly represented by serous cancers, and they are rather estrogen independent. We may observe them arising from the atrophic endometrium [210,212].

Regarding the potential preventive effects of diet intake on EC risk, limited data are available with conclusions of negligible correlation. In their review, Bandera et al. (2009) found an inverse relationship of EC risk with the dietary intake of carotenes, ascorbic acid, and tocopherols. They highlighted that additional larger studies are necessary to confirm this association [213]. Later, a Nurses' Health Study denied such association between EC risk and the consumption of dietary carotenoids and vitamins A, C, or E [214].

The incidence of precancerous changes was found to be higher in overweight and obese patients. Interestingly, higher fat energy intake was found to be associated with increased EC risk, but the energy from carbohydrates and proteins did not increase that risk [215]. Therefore, it was interesting for researchers to explore the role of diet in the pathophysiology of EC in the context of inflammation. Studies have suggested that elevated levels of prostaglandins might underlie the transformation of a normal endometrium into neoplastic tissue, which might be attributed to inflammation-induced cell division with subsequent possibility of ineffective DNA repair and mutations. Interestingly, polyunsaturated fatty acids (e.g., available in seafood) are thought to be anti-inflammatory, and one might think play a possible beneficial role against EC. For example, Brasky et al. (2014) showed that high consumption of dietary eicosapentaenoic acid and docosahexaenoic acid increased the risk of EC by $80 \%$ compared to a lower consumption rate [216]. Alcohol was thought to increase EC risk via increasing the circulating serum sex steroids. Rinaldi et al. (2006) showed that sex-hormone-binding globulin levels are approximately $15 \%$ lower in alcohol consumers ( $25 \mathrm{~g}$ of alcohol daily) compared with non-consumers [217]. Interestingly, recent data from a prospective study performed in 301,051 European women showed that alcohol consumption is not associated with EC risk [218].

The effect of some plant-derived compounds on EC is attributed to their hormonal effect, for example, phytoestrogens, which have low estrogenic activity, while others might possess antioxidant and antimutagenic properties [219]. Flavonoids are a class of polyphenolic metabolites that have antioxidant and anti-mutagenic properties, so it is believed that they may reduce cancer risk, e.g., in EC [220]. Unfortunately, it has not been confirmed in further studies. A randomized controlled trial by Wang et al. (2009) revealed no association between selected flavones and flavonols and EC risk [221]. Similarly, Bandera et al. (2009) showed no association between isoflavones and EC [222]. However, slightly different data were presented by Ollberding et al. (2012), who demonstrated that a greater consumption of isoflavone-containing foods was associated with a reduced risk of EC in postmenopausal women [223]. This might be explained by the fact that isoflavones possess some selective estrogen receptor modulator activity, with varying estrogenic and antiestrogenic potential, depending on the receptor characteristics of the target tissue. Isoflavones are abundant in soy, whose consumption has been studied in numerous publications. A review by Zhang et al. (2015) revealed that soy intake might be 
associated with lower EC risk; however, the authors highlighted that the exact mechanisms are still unknown [224]. Furthermore, a meta-analysis by Zhong et al. (2018) revealed that the consumption of larger amounts of dietary isoflavones from soy products and legumes weakly decreased the risk of EC in the selected population [225]. Remarkably, some authors indicated a negative effect of high soy isoflavone consumption that resulted in a relatively high incidence of endometrial hyperplasia [226]. Therefore, the protective effect of soy isoflavones on EC should be interpreted with caution, and their introduction into cancer therapy might be rather challenging now.

If it is about other compounds, the data are scarce. An inverse association between ultraviolet irradiance and EC incidence was demonstrated, suggesting a possible beneficial effect of vitamin D, considering its multitargeted effects [227]. However, available meta-analyses have revealed no significant relationship between the intake of vitamin $\mathrm{D}$ and the incidence of EC [228]. In a study by Bandera et al. (2009), increased intake of quercetin (a bitter plant flavonol found in different fruits and vegetables) was associated with a decreased risk of EC [222]. Similarly, kaempferol, a natural dietary flavonoid, was explored against EC cells, considering its anticancer, anti-inflammatory, and antioxidant properties, and studies have shown that it suppresses cellular proliferation through various mechanisms $[229,230]$.

Some research was conducted on the association between tea consumption and the risk of EC. In 2015, Yang et al. demonstrated little or no association between tea consumption and the risk of EC [231], while a meta-analysis published later highlighted that a higher dietary intake of green tea might be connected with a reduced risk of EC. Notably, such correlation was not demonstrated in the case of black tea. The authors suggested that the reduced risk might be due to the markedly higher content of catechins in green tea in comparison with black tea. Catechins, such as EGCG, may modulate the estrogen-induced activation of endometrial cells and also induce the apoptosis of neoplastic cells as well as cell cycle arrest [232].

Taking all together, available data on the effect of nutritional compounds on EC pathophysiology are of poor quality and insufficient. Nevertheless, exploring new natural dietary compounds in the prophylaxis or treatment of this disease is encouraged.

\subsection{Ovarian Cancer}

Ovarian cancer is a malignant tumor of the ovaries, occurring mainly in peri- or postmenopausal women. Unfortunately, it is associated with the poorest prognosis and the highest mortality rate among all gynecological cancers [233]. Research shows that the number and frequency of ovulations in a woman's lifetime are linked to the risk of her developing ovarian cancer [234], since it is associated with the rupture of the ovarian epithelium and the sensitizing effect of the follicular fluid with a high content of estrogens [235]. Ovarian cancers are histologically and clinically divided into two different types. Type I cancers are low-grade endometrioid, mucinous, and clear-cell cancers, whereas type II cancers are of a higher histological grade in which tumors may develop de novo from the tubal and/or ovarian surface epithelium and include serous cancers [234]. Surgery is the critical modality in the treatment of ovarian cancer, as well as chemotherapy [234]. Regrettably, due to the unclear etiology of ovarian cancer, it may not always be prevented. However, some factors have been shown to limit the risk of its development, e.g., lactation or the use of combined oral contraception. Therefore, exploring the potential role of nutritional compounds in prophylaxis or supportive treatment is valid.

The available literature suggests a possible link between ovarian cancer and inappropriate dietary habits. For instance, chronic inflammation was implied as an underlying mechanism contributing to ovarian carcinogenesis [236]. A study by Shivappa et al. (2016) showed that ovarian cancer risk increases in women who consume higher amounts of pro-inflammatory products [237]. On the contrary, Dolecek et al. (2010) and Playdon et al. (2017) demonstrated the influence of a healthy diet on the clinical course of ovarian cancer $[238,239]$. The former study showed that only yellow and cruciferous vegetables 
significantly favored the survival rate, whereas a negative correlation was shown for meat [238]. Playdon et al. (2017) demonstrated a trend toward lower mortality with higher fruit intake. Moreover, a higher intake of green leafy vegetables was inversely associated with mortality. Compared to the previously discussed study, the authors did not show such a strong influence of cruciferous vegetables [239]. An important meta-analysis published by Qiu et al. revealed that a high consumption of total, saturated, and trans fats increased ovarian cancer risk. The authors emphasized that different histological subtypes had different susceptibilities to dietary fat, and provided an example of saturated fats that might increase the overall risk of serous and endometrioid ovarian cancers [240].

A variety of studies are available considering phytoestrogens, including the beneficial effect of isoflavones on ovarian cancer, with nonconclusive findings. In a study by Bandera et al. (2011), phytoestrogen presented a trend for a reduction in ovarian cancer risk. However, no significant associations were found. However, an inverse association with total phytoestrogen consumption was found after adjusting for age, race, education, body mass index, and total energy [241]. Moreover, an analysis by Neill et al. (2014) showed a pattern of inverse associations between the increasing intake of phytoestrogens, isoflavones, or lignans and the risk of ovarian cancer, but it should be emphasized that significance was only proved for two lignans-matairesinol and lariciresinol [242]. Isoflavones were found to have a protective effect against ovarian cancer, which may be attributed to the inhibition of the growth and proliferation of ovarian cell lines. Furthermore, they may regulate cancer inflammation pathways [188]. Conversely, Hedelin et al. (2010) found no association between phytoestrogens, fiber intake, and ovarian cancer risk. The authors found that fiber and coumestrol intake was inversely associated with borderline tumors but not with invasive types [243]. Finally, in 2016, Hua et al. showed in their meta-analysis that the intake of dietary flavonoids might decrease ovarian cancer risk. According to this analysis, ovarian cancer risk decreases with isoflavones and flavonols, but there was no evidence that the dietary intake of flavones was protective in the case of ovarian cancer [244].

Herein, we present some examples of such flavonoids that might offer beneficial effects against ovarian cancer. Quercetin, a plant flavonol, inhibits oxidation and acts as a free-radical scavenger with estrogenic activities on both types of estrogen receptors $(\alpha$ and $\beta$ ) [87]. Quercetin presented antitumor and anti-inflammatory properties with a cytotoxic influence on ovarian cancer, which Shafabakhsh et al. attributed to its antiinflammatory, pro-oxidative, antiproliferation, and apoptosis induction activities [245]. A different already described flavonoid, kaempferol, was also found to be a good inhibitor of angiogenesis [246]. Finally, a flavonol named galangin was found to be selective against cancer cells where it induced apoptosis. It was suggested that future research might prove its usability in platinum-resistant ovarian cancers [247].

Curcumin is a well-known natural compound found in turmeric. It is a diarylheptanoid and belongs to the group of curcuminoids, which are natural phenols. Curcumin exhibited a wide range of effects, e.g., anticancer, anti-inflammatory, and antioxidant capabilities. In 2007, Lin et al. showed that curcumin might inhibit nuclear factor kappa B activation and suppress both proliferation and angiogenesis in ovarian cancer cells [248]. Since curcumin has been extensively studied in cancer treatment, data might suggest additional efficacy due to sensitization of the resistance of cancer cells to current therapies [249]. For example, a study conducted by Wahl et al. (2007) demonstrated that curcumin used in a combination with a special anticancer ligand (Apo2L) results in reduced chemoresistance to conventional chemotherapeutic agents [250]. More recently, He et al. (2016) found that curcumin significantly increases epithelial ovarian cancer sensitivity to cisplatin and abolishes the sphere-forming ability [251]. An earlier study by Yallapu et al. in 2010 showed that this compound reduces the dose of both radiation and cisplatin needed for cell growth suppression in cisplatin-resistant ovarian cancer cells [252]. Berberine is a plant-based alkaloid with a tetracyclic skeleton with anti-inflammatory, antiproliferative, pro-apoptotic, and antimetastatic actions [253]. A recent study by Liu et al. (2019) proposed that the co-use of berberine and cisplatin enhances ovarian cancer cell death by inducing apoptosis 
and necroptosis. Tissue samples revealed the typical apoptotic and necrotic cell death morphology with the inhibition of proliferating cell nuclear antigen and Ki67 and a higher expression of selected caspases [254].

Finally, we highlight new agents that might be of interest for future research on ovarian cancer therapy. The first is honokiol, a natural biphenolic lignan extracted from different parts of magnolia. Regarding the possible effects on ovarian cancer, honokiol regulates the nuclear factor kappa B activation pathway and VEGF expression [255]. Recently, a study showed that the anticancer activities of honokiol in ovarian cancer cells are mediated through the activation of adenosine $5^{\prime}$ phosphate-activated protein kinase. Honokiol induced apoptosis with the activation of various caspases. Moreover, honokiol inhibited the migration and invasion of ovarian cancer cells [256]. The second new compound is bufalin, which is a steroid isolated from toad venom. According to available studies, bufalin presents antitumor effects against various malignancies, including lung cancer [257]. A study by Su et al. published in 2020 demonstrated its usefulness in ovarian cancer, where it acted as a potent inhibitor of cell growth and migration in ovarian cancer cells through the suppression of mTOR activation and hypoxia-inducible factor 1-alpha (HIF1 $\alpha)$ induction. The authors concluded that bufalin might be used as an additive to cisplatin in ovarian cancer therapy [258]. Lastly, tetramethylpyrazine (also named ligustrazine) is a chemical compound classified as an alkylpyrazine found in fermented soybeans and cocoa beans [259]. It is a natural compound reported to present anticancer activity. In 2020, Zhang et al. found that tetramethylpyrazine inhibits the viability, proliferation, migration, and invasion ability of selected ovarian cancer cell lines in a dose-dependent manner [260].

Vitamin D may be significant in reproductive organ tumors [261]. A systematic review of the literature has not identified any human studies regarding the effect of vitamin D or its analogues on ovarian cancer patients, and such supplementation or treatment cannot be recommended [262]. Regardless of vitamin D, calcium seems to be significant in the pathophysiology and therapy of ovarian cancer. An available meta-analysis by Song et al. published in 2017 supported the hypothesis that increased calcium intake might reduce ovarian cancer risk. In the analysis, dietary calcium was significantly associated with a reduced risk of ovarian cancer among cohort and case-control studies. However, the authors concluded that further studies, mostly those on larger groups, might lead to more decisive conclusions [263].

Although the discussed data indicated some influence of nutritional compounds on the development and course of ovarian cancer, there is a paucity of valuable clinical data that may be translated into evidence-based medicine. Flavonoids seem to play the most significant role. However, more research is encouraged in order to explore novel compounds.

\section{Menstrual Disorders}

\subsection{Menorrhagia}

Menorrhagia is described as excessive uterine bleeding, in terms of flow and duration, during regular cyclical intervals. Its clinical definition includes blood loss greater than $80 \mathrm{~mL}$ per cycle or menses lasting longer than 7 days [264]. Diet should be considered when managing menorrhagia. Ideally, the diet should be low in animal fat and rich in fish oils and linolenic and linoleic acids. Therefore, flaxseeds and soy protein have been frequently suggested due to their ability to regulate the menstrual cycle [265]. Here, we briefly discuss supplements and nutrients that have been explored for their potential role in managing menorrhagia.

\subsubsection{Iron}

Blood loss is one of the major causes of iron deficiency anemia. However, it is less well known that chronic iron deficiency can be a contributor to menorrhagia, in turn. Therefore, women experiencing heavy blood loss should consume iron-rich foods such as Brewer's yeast, wheat germ, blackstrap molasses, organic liver and kidneys, apricots, eggs, ground 
beef, raisins, beans, cooked spinach, and chicken. In addition, yogurt, sour fruits, and citrus juices can aid in the absorption of iron [266].

\subsubsection{Vitamin A}

Adult women experiencing menorrhagia may have low levels of vitamin A. One study in which vitamin A was used to treat women with menorrhagia showed that those who received 60,000 IU of vitamin A for 35 days experienced both a return to normal and a reduction in blood loss compared to the placebo group [264,267].

\subsubsection{Vitamin B Complex}

Vitamin B deficiency may be related to menorrhagia. Studies have shown that vitamin $B$ complex deficiencies result in failure of the liver to inactivate estrogen. Thus, the excess estrogen's effect on the endometrium ends up with more bleeding, while vitamin B complex may help normalize estrogen metabolism and thus reduce bleeding [268].

\subsubsection{Vitamin $\mathrm{C}$ and Bioflavonoids}

Vitamin $\mathrm{C}$ and bioflavonoids improve heavy bleeding via making the capillary walls less fragile. Livdans-Forret noted that 16 of 18 women who took vitamin $C$ and bioflavonoids for heavy menstrual bleeding reported an improvement [264]. Moreover, vitamin $C$ can benefit women with iron deficiency due to menorrhagia by increasing iron absorbency [269].

Some herbal and nutritional supplements have shown beneficial effects against menorrhagia, including the chaste tree or chasteberry (Vitex agnus castus), which is a well-known herb in Europe for the treatment of hormonal imbalances and abnormal bleeding in women. In addition, astringent herbs such as shepherd's purse have a long history of use for inhibiting gynecological hemorrhage. Tonic herbs such as life root, also known as ragwort, have been used for conditions such as menstrual cramps, menorrhagia, and subdued menstruation. Traditional herbs such as yarrow have been used since medieval times to treat bleeding wounds. Yarrow is a uterine stimulant that increases muscular tone, stimulates reproductive activity, and effectively treats menstrual problems [264].

\subsection{Dysmenorrhea}

Dysmenorrhea is commonly described as painful menstruation in the form of lower abdominal pain, which has a range of severity and associated symptoms. These include nausea, vomiting and loss of appetite, fatigue, diarrhea, headache, restlessness, insomnia, and fainting [270]. Primary dysmenorrhea has been primarily associated with the extra production of prostaglandins and leukotrienes. Prostaglandins (PGF2- $\alpha$ ) temporarily limit or stop the blood supply to the uterus by stimulating its contraction, which reduces the amount of blood perfusing the uterus through myometrial compression of the blood vessels. This deprives the uterus of oxygen, which results in cramping and abdominal pain. Higher concentrations of PGF2- $\alpha$ and leukotrienes in menstrual blood and in uterine smears were observed in women with signs of painful menstruation. Several studies have explored the efficacy of supplements and nutrients against dysmenorrhea [271-273], which we discuss next in the article.

\subsubsection{Calcium and Magnesium}

Dietary calcium and magnesium intake has a protective effect against dysmenorrhea. Following absorption from the upper intestine, they can manage the muscle cells' response to nerve stimuli through numerous functions [274]. Even though the tocolytic effect of magnesium has already been proven in vivo and in vitro, the best dosage for treating or preventing dysmenorrhea is not yet clear [275]. 


\subsubsection{Olive Oil}

The polyphenolic compound oleocanthal in extra virgin olive oil has been shown to have anti-inflammatory and antioxidant effects. A study examining its inhibitory effect on prostaglandin-induced uterine hypercontraction showed that oleocanthal, dosedependently, inhibited the PGF2 $\alpha$-induced contraction amplitude [276]. Thus, the authors concluded that extra virgin olive oil and oleocanthal can reduce oxidative stress and uterine hypercontraction.

\subsubsection{Fennel}

Fennel, or Foeniculum vulgare, is a herbal therapy proposed to alleviate menstrual pain by lowering the prostaglandin levels in blood. A meta-analysis showed the equivalent effects of fennel on pain reduction compared with drug therapy, and the pooled results showed favorable effects of fennel on pain reduction compared to the placebo [277]. Fennel in the form of capsules, pill, or oils (excluding massage oil) was used in the 12 studies included in the meta-analysis.

\subsubsection{Dietary Fiber}

Since dietary fat and fiber alter estrogen levels, they may be related to dysmenorrhea by affecting hormones. Fiber intake reduces blood estrogen levels, whereas fat has been associated with increased estrogen levels. Nagata et al. found that intake of dietary fiber is significantly inversely correlated with the menstrual pain scale after adjusting for age, smoking status, age at menarche, and total energy intake [278].

\subsubsection{Omega-3 and Omega-6 Fatty Acids}

Western diets are rich in omega- 6 fatty acids (e.g., vegetable oil, eggs, and margarine) but poor in omega- 3 fatty acids (e.g., fish, canola oil, and wheat germ). Omega- 6 fatty acids contribute to the formation of pro-inflammatory eicosanoids, such as Prostaglandin E2 (PGE2), thromboxane A2, and leukotriene B4, whereas omega-3 fatty acids, specifically eicosapentanoic and docosahexanoic acids, lead to the formation of less inflammatory eicosanoids (e.g., PGE3, thromboxane A3, and leukotriene B5). There is some epidemiologic evidence that a diet rich in omega- 3 fatty acids can decrease painful menses. Several studies have shown a significant decrease in menstrual pain in those using fish oil $[279,280]$.

\subsubsection{Vitamin D}

Vitamin D receptors are located in the human uterus, and vitamin D inhibits the synthesis of prostaglandins [144]. Calcitriol (1,25[OH]2D) decreases, in vitro, the level of pro-inflammatory cytokines such as interleukin 6 and tumor necrosis factor and regulates the expression of several key genes involved in the prostaglandin pathway, causing decreased biological activity of prostaglandins [144]. Thus, vitamin D has been suggested to halt the extra prostaglandin production found in primary dysmenorrhea. One study showed an inverse correlation of 25(OH)D levels with the pain score as well as a significant reduction in pain in women taking vitamin $\mathrm{D}$, with the greatest reduction found in women who reported severe pain at baseline [281]. Studies in Iran and Italy have shown that the use of a single dose of oral cholecalciferol (300,000 IU) for five days before the beginning of menstrual bleeding significantly decreased the pain of severe primary dysmenorrhea, while another trial found that the administration of 50,000 IU of vitamin D for eight weeks significantly reduced pain severity [282]. Another study found that low levels of vitamin $\mathrm{D}$ are inversely related to the severity of primary dysmenorrhea and that vitamin $\mathrm{D}$ and calcium intake could reduce its severity [283].

\subsubsection{Vitamin E}

Vitamin $E$ is thought to reduce prostaglandin formation by inhibiting arachidonic acid release. A review article about the positive effects of vitamin $E$ on the alleviation of primary dysmenorrhea pain showed a significant reduction in pain severity in women treated with 
this vitamin [264]. Two studies have shown a significant reduction in pain when 150 to 500 $\mathrm{IU} /$ day of vitamin $\mathrm{E}$ was administered a few days before and during menses compared with the placebo for two to three cycles [264].

\subsubsection{Qixuehe}

Formulations of Chinese herbs may be beneficial but lack rigorous testing to evaluate their mechanistic action. One study found that QiXueHe Capsule (QXHC) can alleviate pathological changes in menstrual disorders. Researchers identified 1022 targets of 15 herbs in QXHC to investigate its pharmacological mechanisms on menstrual disorders. Results showed that targets in the treatment of menstrual disorders are significantly associated with several biological pathways, such as VEGF and chemokine signaling pathways and alanine, aspartate, and glutamate metabolism, which are involved in the major pathological processes of menstrual disorders. The authors also found 20 pairs of QXHC candidate targets, and the corresponding chemical components had the strong binding free energy. These results showed that the pharmacological mechanisms of QXHC in the treatment of menstrual disorders may be associated with its involvement in hemopoiesis, analgesia, nutrient absorption and metabolism, mood regulation, as well as immune modulation [284].

\subsubsection{Zinc}

Zinc has been found to reduce the synthesis of prostaglandins via its action as an endogenous antioxidant catalyst and as an anti-inflammatory agent that can improve microcirculation of endometrial tissue. This was shown in a study that found that zinc significantly lowered the pain duration and severity in women compared to the control group and improved the patients' quality of life [285]. One study suggested that daily intake of $30 \mathrm{mg}$ of zinc one to four days prior to menstruation can prevent menstrual cramping pain, without harmful side effects, while another showed evidence that zinc can treat primary dysmenorrhea in adolescent girls [286].

\subsubsection{Vitamin $\mathrm{K}$}

A few studies have investigated vitamin $\mathrm{K}$ (phylloquinone) injection to treat primary dysmenorrhea. Treatment with vitamin K may shorten the length of the extended menstrual flow due to its action on prothrombin, which is a coagulation protein produced in the liver and is dependent on vitamin $\mathrm{K}$ [287]. Chao et al. reported that women indicated a significant decrease in pain after vitamin $\mathrm{K}$ injection in both legs and increased plasma phylloquinone levels [287]. Wade et al. noted that both women given vitamin K3 using an acupuncture point injection or deep muscle injection experienced a decrease in average pain as well as menstrual distress [288]. It was suggested that women with severe primary dysmenorrhea could manage severe dysmenorrhea with two vitamin K acupuncture point injections per year.

Finally, an interesting recent study examined the relationship of breakfast to the development of future reproductive diseases. Missing this first meal interferes with the start of the active phase during the circadian rhythm that is regulated by the central clock system. Since both food intake and the light/dark cycle are the main regulators of circadian rhythms, skipping breakfast can lead to changes in light stimulation within the central clock system [289]. The authors suggested that meal skipping affects the hypothalamicpituitary-ovarian axis, impairs the reproductive rhythm, and leads to ovarian dysfunction. Young women who skip breakfast show significantly higher incidences of dysmenorrhea and irregular menstruation, suggesting that missing meals affects ovarian and uterine functions [289]. Since dysmenorrhea becomes more manifested in those with a history of dieting, the authors posited that inadequate dietary habits in adolescence become a trigger for the subsequent development of organic gynecological diseases. [289]. Thus, they suggested shifting the focus from therapeutic to prophylactic and from dietary content to dietary timing in the management of gynecological disorders in young women. 
Further investigation, together with developing new methods, is recommended to test their hypothesis.

\section{Conclusions}

Gynecological diseases, like other diseases, have a causal relationship with some factors in the environment. These factors may be physical or/and social. Someone may suffer from gynecological diseases either due to her physical condition/exposure (e.g., nutritional status, environment, exposure to bacteria or viruses, etc.) or due to social conditions (education, income level, culture, etc.). So, while dealing with a gynecological disease clinically, it is recommended to look at these factors that might improve the outcome. In this article, we covered several dietary supplements and nutrients that may provide potential benefits upon implementation in preventive/therapeutic measures to control common gynecological diseases, including uterine fibroids, endometriosis, PCOS, infertility, menstrual disorders, and vaginal infections, as well as malignant cancers such as cervical cancer, endometrial cancer, and ovarian cancer. Nutrition has the most important lifelong environmental impact on human health. There are several studies indicating that fruits, tea, vegetables, as well as various dietary compounds can alter several signaling pathways involved in disease pathogenesis as well as impact cancer cells, such as the activation of tumor suppressor genes and an increase in apoptosis and the activity of cell survival proteins, thus playing a protective role against cancer. However, this research area needs more attention.

Author Contributions: Conceptualization, A.A.-H. and M.A. Authors of sections: Sources and writing original draft-M.C. and C.W.; gynecological cancers-S.E.; endometriosis and PCOS-H.S.; uterine fibroids and infertility-L.P.; menstrual disorders-H.E.; microbiome and infections-review and editing, M.A.; supervision, A.A.-H. and M.A.; funding acquisition, A.A.-H. All authors have read and agreed to the published version of the manuscript.

Funding: This study was supported in part by the National Institutes of Health grants R01 HD09437804, R01 ES 028615-02, R01 HD100367-01, U54 MD007602, and R01 HD094380-02.

Institutional Review Board Statement: Not applicable.

Informed Consent Statement: Not applicable.

Data Availability Statement: Not applicable.

Conflicts of Interest: Ayman Al-Hendy has been a consultant and participated in advisory boards for Allergan plc, Bayer, Repros, Myovant, MD Stem Cells, AstraZeneca, Wyeth, and AbbVie. The rest of the authors declare no conflict of interest.

\section{References}

1. Izetbegovic, S.; Alajbegovic, J.; Mutevelic, A.; Pasagic, A.; Masic, I. Prevention of diseases in gynecology. Int. J. Prev. Med. 2013, 4, 1347-1358.

2. Kussmann, M.; Fay, L.B. Nutrigenomics and personalized nutrition: Science and concept. Per. Med. 2008, 5, 447-455. [CrossRef]

3. Herceg, Z. Epigenetics and cancer: Towards an evaluation of the impact of environmental and dietary factors. Mutagenesis 2007, 22, 91-103. [CrossRef]

4. Junien, C. Impact of diets and nutrients/drugs on early epigenetic programming. J. Inherit. Metab. Dis. 2006, 29, 359-365. [CrossRef]

5. Dolinoy, C.D.; Weidman, J.R.; Jirtle, R.L. Epigenetic gene regulation: Linking early developmental environment to adult disease. Reprod. Toxicol. 2007, 23, 297-307. [CrossRef]

6. Paluszczak, J.; Krajka-Kuzniak, V.; Baer-Dubowska, W. The effect of dietary polyphenols on the epigenetic regulation of gene expression in MCF7 breast cancer cells. Toxicol. Lett. 2010, 192, 119-125. [CrossRef] [PubMed]

7. Andreescu, N.; Puiu, M.; Niculescu, M. Effects of Dietary Nutrients on Epigenetic Changes in Cancer. Methods Mol. Biol. 2018, 1856, 121-139.

8. Stephen, H.E.; Chandra, A. Declining estimates of infertility in the United States: 1982-2002. Fertil. Steril. 2006, 86, 516-523. [CrossRef] [PubMed]

9. Braga, D.P.; Halpern, G.; Setti, A.S.; Figueira, R.C.; Iaconelli, A., Jr.; Borges, E., Jr. The impact of food intake and social habits on embryo quality and the likelihood of blastocyst formation. Reprod. Biomed. Online 2015, 31, 30-38. [CrossRef] [PubMed] 
10. Chavarro, J.E.; Rich-Edwards, J.W.; Rosner, B.A.; Willett, W.C. Protein intake and ovulatory infertility. Am. J. Obstet. Gynecol. 2008, 198, 210-e1. [CrossRef] [PubMed]

11. Gaskins, J.A.; Chavarro, J.E. Diet and fertility: A review. Am. J. Obstet. Gynecol. 2018, 218, 379-389. [CrossRef] [PubMed]

12. Czeizel, E.A.; Bartfai, Z.; Banhidy, F. Primary prevention of neural-tube defects and some other congenital abnormalities by folic acid and multivitamins: History, missed opportunity and tasks. Ther. Adv. Drug Saf. 2011, 2, 173-188. [CrossRef] [PubMed]

13. García-Fernández, E.; Rico-Cabanas, L.; Rosgaard, N.; Estruch, R.; Bach-Faig, A. Mediterranean diet and cardiodiabesity: A review. Nutrients 2014, 6, 3474-3500. [CrossRef] [PubMed]

14. Karayiannis, D.; Kontogianni, M.D.; Mendorou, C.; Mastrominas, M.; Yiannakouris, N. Adherence to the Mediterranean diet and IVF success rate among non-obese women attempting fertility. Hum. Reprod. 2018, 33, 494-502. [CrossRef] [PubMed]

15. Vujkovic, M.; de Vries, J.H.; Lindemans, J.; Macklon, N.S.; van der Spek, P.J.; Steegers, E.A.; Steegers-Theunissen, R.P. The preconception Mediterranean dietary pattern in couples undergoing in vitro fertilization/intracytoplasmic sperm injection treatment increases the chance of pregnancy. Fertil. Steril. 2010, 94, 2096-2101. [CrossRef]

16. Twigt, J.M.; Bolhuis, M.E.; Steegers, E.A.; Hammiche, F.; Van Inzen, W.G.; Laven, J.S.; Steegers-Theunissen, R.P. The preconception diet is associated with the chance of ongoing pregnancy in women undergoing IVF/ICSI treatment. Hum. Reprod. 2012, 27, 2526-2531. [CrossRef]

17. Gaskins, A.J.; Chiu, Y.H.; Williams, P.L.; Keller, M.G.; Toth, T.L.; Hauser, R.; Chavarro, J.E.; EARTH Study Team. Maternal whole grain intake and outcomes of in vitro fertilization. Fertil. Steril. 2016, 105, 1503-1510e4. [CrossRef]

18. Mumford, S.L.; Browne, R.W.; Kim, K.; Nichols, C.; Wilcox, B.; Silver, R.M.; Connell, M.T.; Holland, T.L.; Kuhr, D.L.; Omosigho, U.R.; et al Preconception plasma phospholipid fatty acids and fecundability. J. Clin. Endocrinol. Metab. 2018, 103, 4501-4510. [CrossRef]

19. Saldeen, P.; Saldeen, T. Women and omega-3 Fatty acids. Obstet. Gynecol. Surv. 2004, 59, 722-730. [CrossRef]

20. Abadia, L.; Gaskins, A.J.; Chiu, Y.H.; Williams, P.L.; Keller, M.; Wright, D.L.; Souter, I.; Hauser, R.; Chavarro, J.E.; Enviroment and Reproductive Health Study Team. Serum 25-hydroxyvitamin D concentrations and treatment outcomes of women undergoing assisted reproduction. Am. J. Clin. Nutr. 2016, 104, 729-735.

21. Polyzos, N.P.; Anckaert, E.; Guzman, L.; Schiettecatte, J.; Van Landuyt, L.; Camus, M.; Smitz, J.; Tournaye, H. Vitamin D deficiency and pregnancy rates in women undergoing single embryo, blastocyst stage, transfer (SET) for IVF/ICSI. Hum. Reprod. 2014, 29, 2032-2040. [CrossRef] [PubMed]

22. Chavarro, J.E.; Rich-Edwards, J.W.; Rosner, B.; Willett, W.C. A prospective study of dairy foods intake and anovulatory infertility. Hum. Reprod. 2007, 22, 1340-1347. [CrossRef]

23. Arefi, S.; Khalili, G.; Iranmanesh, H.; Farifteh, F.; Hosseini, A.; Fatemi, H.M.; Lawrenz, B. Is the ovarian reserve influenced by vitamin D deficiency and the dress code in an infertile Iranian population? J. Ovarian Res. 2018, 11, 1-6. [CrossRef]

24. Mg, S.; Brown, J.; Clarke, J.; Rj, H. Antioxidants for female subfertility. Cochrane Database Syst. Rev. 2013, 8, CD007807.

25. Ruder, E.H.; Hartman, T.J.; Reindollar, R.H.; Goldman, M.B. Female dietary antioxidant intake and time to pregnancy among couples treated for unexplained infertility. Fertil. Steril. 2014, 101, 759-766. [CrossRef] [PubMed]

26. Marco, M.L.; Heeney, D.; Binda, S.; Cifelli, C.J.; Cotter, P.D.; Foligné, B.; Gänzle, M.; Kort, R.; Pasin, G.; Pihlanto, A.; et al. Health benefits of fermented foods: Microbiota and beyond. Curr. Opin. Biotechnol. 2017, 44, 94-102. [CrossRef]

27. Atassi, F.; Brassart, D.; Grob, P.; Graf, F.; Servin, A.L. Lactobacillus strains isolated from the vaginal microbiota of healthy women inhibit Prevotella bivia and Gardnerella vaginalis in coculture and cell culture. FEMS Immunol. Med. Microbiol. 2006, 48, 424-432 [CrossRef]

28. Rose, W.A., II; McGowin, C.L.; Spagnuolo, R.A.; Eaves-Pyles, T.D.; Popov, V.L.; Pyles, R.B. Commensal bacteria modulate innate immune responses of vaginal epithelial cell multilayer cultures. PLoS ONE 2012, 7, e32728. [CrossRef] [PubMed]

29. Younis, N.S.; Mahasneh, A. Probiotics and the envisaged role in treating human infertility. Middle E. Fertil. Soc. J. 2020, 25, 1-9. [CrossRef]

30. Bhandari, P.; Prabha, V. Evaluation of profertility effect of probiotic Lactobacillus plantarum 2621 in a murine model. Indian J. Med. Res. 2015, 142, 79-84.

31. Rocha, A.L.; Oliveira, F.R.; Azevedo, R.C.; Silva, V.A.; Peres, T.M.; Candido, A.L.; Gomes, K.B.; Reis, F.M. Recent advances in the understanding and management of polycystic ovary syndrome. F1000Research 2019, 8, 565. [CrossRef]

32. Esfandyari, S.; Chugh, R.M.; Park, H.S.; Hobeika, E.; Ulin, M.; Al-Hendy, A. Mesenchymal Stem Cells as a Bio Organ. for Treatment of Female Infertility. Cells 2020, 9, 2253. [CrossRef] [PubMed]

33. Esfandyari, S. miRNA-92a suppresses androgen-producing steroidogenic genes expression in h295r, a human pcos in-vitro theca-like cell model. Fertil. Steril. 2020, 114, e349-e350. [CrossRef]

34. Azziz, R.; Woods, K.S.; Reyna, R.; Key, T.J.; Knochenhauer, E.S.; Yildiz, B.O. The prevalence and features of the polycystic ovary syndrome in an unselected population. J. Clin. Endocrinol. Metab. 2004, 89, 2745-2749. [CrossRef]

35. Faghfoori, Z.; Fazelian, S.; Shadnoush, M.; Goodarzi, R. Nutritional management in women with polycystic ovary syndrome: A review study. Diabetes Metab. Syndr. Clin. Res. Rev. 2017, 11, S429-S432. [CrossRef]

36. Douglas, C.C.; Gower, B.A.; Darnell, B.E.; Ovalle, F.; Oster, R.A.; Azziz, R. Role of diet in the treatment of polycystic ovary syndrome. Fertil. Steril. 2006, 85, 679-688. [CrossRef]

37. Goss, A.M.; Gower, B.; Soleymani, T.; Stewart, M.; Pendergrass, M.; Lockhart, M.; Krantz, O.; Dowla, S.; Bush, N.; Barry, V.G.; et al Effects of weight loss during a very low carbohydrate diet on specific adipose tissue depots and insulin sensitivity in older adults with obesity: A randomized clinical trial. Nutr. Metab. 2020, 17, 1-12. [CrossRef] 
38. Kasim-Karakas, S.E.; Almario, R.U.; Gregory, L.; Wong, R.; Todd, H.; Lasley, B.L. Metabolic and endocrine effects of a polyunsaturated fatty acid-rich diet in polycystic ovary syndrome. J. Clin. Endocrinol. Metab. 2004, 89, 615-620. [CrossRef] [PubMed]

39. Teegarden, D.; Donkin, S.S. Vitamin D: Emerging new roles in insulin sensitivity. Nutr. Res. Rev. 2009, 22, 82-92. [CrossRef]

40. He, C.; Lin, Z.; Robb, S.W.; Ezeamama, A.E. Serum vitamin D levels and polycystic ovary syndrome: A systematic review and meta-analysis. Nutrients 2015, 7, 4555-4577. [CrossRef]

41. Ott, J.; Wattar, L.; Kurz, C.; Seemann, R.; Huber, J.C.; Mayerhofer, K.; Vytiska-Binstorfer, E. Parameters for calcium metabolism in women with polycystic ovary syndrome who undergo clomiphene citrate stimulation: A prospective cohort study. Eur. J. Endocrinol. 2012, 166, 897. [CrossRef]

42. Wojtusik, J.; Johnson, P.A. Vitamin D regulates anti-Mullerian hormone expression in granulosa cells of the hen. Biol. Reprod. 2012, 86, 1-7. [CrossRef] [PubMed]

43. Iliodromiti, S.; Kelsey, T.W.; Anderson, R.A.; Nelson, S.M. Can anti-Müllerian hormone predict the diagnosis of polycystic ovary syndrome? A systematic review and meta-analysis of extracted data. J. Clin. Endocrinol. Metab. 2013, 98, 3332-3340. [CrossRef]

44. Elhusseini, H.; Lizneva, D.; Gavrilova-Jordan, L.; Eziba, N.; Abdelaziz, M.; Brakta, S.; Halder, S.; Al-Hebdy, A. Vitamin d and female reproduction. In A Critical Evaluation of Vitamin D: Basic Overview; Gower, S., Ed.; IntechOpen: London, UK, $2017 ;$ p. 297.

45. Irani, M.; Minkoff, H.; Seifer, D.B.; Merhi, Z. Vitamin D increases serum levels of the soluble receptor for advanced glycation end products in women with PCOS. J. Clin. Endocrinol. Metab. 2014, 99, E886-E890. [CrossRef]

46. Legro, R.S.; Arslanian, S.A.; Ehrmann, D.A.; Hoeger, K.M.; Murad, M.H.; Pasquali, R.; Welt, C.K. Diagnosis and treatment of polycystic ovary syndrome: An Endocrine Society clinical practice guideline. J. Clin. Endocrinol. Metab. 2013, 98, 4565-4592. [CrossRef]

47. Rodriguez Paris, V.; Bertoldo, M.J. The mechanism of androgen actions in PCOS etiology. Med. Sci. 2019, 7, 89. [CrossRef]

48. Zhang, X.; Zheng, Y.; Guo, Y.; Lai, Z. The effect of low carbohydrate diet on polycystic ovary syndrome: A meta-analysis of randomized controlled trials. Int. J. Endocrinol 2019. [CrossRef]

49. Ebrahimi, R.; Bahiraee, A.; Niazpour, F.; Emamgholipour, S.; Meshkani, R. The role of microRNAs in the regulation of insulin signaling pathway with respect to metabolic and mitogenic cascades: A review. J. Cell. Biochem. 2019, 120, 19290-19309. [CrossRef] [PubMed]

50. Emamgholipour, S.; Ebrahimi, R.; Bahiraee, A.; Niazpour, F.; Meshkani, R. Acetylation and insulin resistance: A focus on metabolic and mitogenic cascades of insulin signaling. Crit. Rev. Clin. Lab. Sci. 2020, 57, 196-214. [CrossRef]

51. Moran, L.J.; Noakes, M.; Clifton, P.M.; Tomlinson, L.; Norman, R.J. Dietary composition in restoring reproductive and metabolic physiology in overweight women with polycystic ovary syndrome. J. Clin. Endocrinol. Metab. 2003, 88, 812-819. [CrossRef] [PubMed]

52. Jamilian, M.; Asemi, Z. The effects of soy isoflavones on metabolic status of patients with polycystic ovary syndrome. TJ Clin. Endocrinol. Metab. 2016, 101, 3386-3394. [CrossRef]

53. Khani, B.; Mehrabian, F.; Khalesi, E.; Eshraghi, A. Effect of soy phytoestrogen on metabolic and hormonal disturbance of women with polycystic ovary syndrome. J. Res. Med. Sci. Off. J. Isfahan Univ. Med. Sci. 2011, 16, 297.

54. Tehrani, H.G.; Allahdadian, M.; Zarre, F.; Ranjbar, H.; Allahdadian, F. Effect of green tea on metabolic and hormonal aspect of polycystic ovarian syndrome in overweight and obese women suffering from polycystic ovarian syndrome: A clinical trial. J. Educ. Health Promot. 2017, 6, 36. [CrossRef] [PubMed]

55. Armanini, D.; Mattarello, M.J.; Fiore, C.; Bonanni, G.; Scaroni, C.; Sartorato, P.; Palermo, M. Licorice reduces serum testosterone in healthy women. Steroids 2004, 69, 763-766. [CrossRef]

56. MCalderon-Montano, J.; Burgos-Morón, E.; Pérez-Guerrero, C.; López-Lázaro, M. A review on the dietary flavonoid kaempferol. Mini Rev. Med. Chem. 2011, 11, 298-344. [CrossRef]

57. Tabrizi, F.P.; Hajizadeh-Sharafabad, F.; Vaezi, M.; Jafari-Vayghan, H.; Alizadeh, M.; Maleki, V. Quercetin and polycystic ovary syndrome, current evidence and future directions: A systematic review. J. Ovarian Res. 2020, 13, 11. [CrossRef]

58. Shah, K.N.; Patel, S.S. Phosphatidylinositide 3-kinase inhibition: A new potential target for the treatment of polycystic ovarian syndrome. Pharm. Biol. 2016, 54, 975-983. [CrossRef]

59. Wang, Z.; Zhai, D.; Zhang, D.; Bai, L.; Yao, R.; Yu, J.; Cheng, W.; Yu, C. Quercetin decreases insulin resistance in a polycystic ovary syndrome rat model by improving inflammatory microenvironment. Reprod. Sci. 2017, 24, 682-690. [CrossRef]

60. Rezvan, N.; Moini, A.; Gorgani-Firuzjaee, S.; Hosseinzadeh-Attar, M.J. Oral quercetin supplementation enhances adiponectin receptor transcript expression in polycystic ovary syndrome patients: A randomized placebo-controlled double-blind clinical trial. Cell J. 2018, 19, 627.

61. Khorshidi, M.; Moini, A.; Alipoor, E.; Rezvan, N.; Gorgani-Firuzjaee, S.; Yaseri, M.; Hosseinzadeh-Attar, M.J. The effects of quercetin supplementation on metabolic and hormonal parameters as well as plasma concentration and gene expression of resistin in overweight or obese women with polycystic ovary syndrome. Phytother. Res. 2018, 32, 2282-2289. [CrossRef]

62. Oh, J.S.; Kim, H.; Vijayakumar, A.; Kwon, O.; Choi, Y.J.; Huh, K.B.; Chang, N. Association between dietary flavanones intake and lipid profiles according to the presence of metabolic syndrome in Korean women with type 2 diabetes mellitus. Nutr. Res. Pract. 2016, 10, 67-73. [CrossRef]

63. Romualdi, D.; Costantini, B.; Campagna, G.; Lanzone, A.; Guido, M. Is there a role for soy isoflavones in the therapeutic approach to polycystic ovary syndrome? Results from a pilot study. Fertil. Steril. 2008, 90, 1826-1833. [CrossRef] 
64. Banaszewska, B.; Wrotyńska-Barczyńska, J.; Spaczynski, R.Z.; Pawelczyk, L.; Duleba, A.J. Effects of resveratrol on polycystic ovary syndrome: A double-blind, randomized, placebo-controlled trial. J. Clin. Endocrinol. Metab. 2016, 101, 4322-4328. [CrossRef]

65. Günalan, E.; Yaba, A.; Yılmaz, B. The effect of nutrient supplementation in the management of polycystic ovary syndromeassociated metabolic dysfunctions: A critical review. J. Turk. Ger. Gynecol. Assoc. 2018, 19, 220. [CrossRef]

66. Anderson, R.A. Chromium in the prevention and control of diabetes. Diab. Metab. 2000, 26, 22-28.

67. Chakraborty, P.; Ghosh, S.; Goswami, S.K.; Kabir, S.N.; Chakravarty, B.; Jana, K. Altered trace mineral milieu might play an aetiological role in the pathogenesis of polycystic ovary syndrome. Biol. Trace Elem. Res. 2013, 152, 9-15. [CrossRef]

68. Lucidi, R.S.; Thyer, A.C.; Easton, C.A.; Holden, A.E.; Schenken, R.S.; Brzyski, R.G. Effect of chromium supplementation on insulin resistance and ovarian and menstrual cyclicity in women with polycystic ovary syndrome. Fertil. Steril. 2005, 84, 1755-1757. [CrossRef] [PubMed]

69. Jamilian, M.; Asemi, Z. Chromium supplementation and the effects on metabolic status in women with polycystic ovary syndrome: A randomized, double-blind, placebo-controlled trial. Ann. Nutr. Metab. 2015, 67, 42-48. [CrossRef]

70. Jamilian, M.; Bahmani, F.; Siavashani, M.A.; Mazloomi, M.; Asemi, Z.; Esmaillzadeh, A. The effects of chromium supplementation on endocrine profiles, biomarkers of inflammation, and oxidative stress in women with polycystic ovary syndrome: A randomized, double-blind, placebo-controlled trial. Biol. Trace Elem. Res. 2016, 172, 72-78. [CrossRef] [PubMed]

71. Ullah, G.; Jung, P.; Machaca, K. Modeling Ca2+ signaling differentiation during oocyte maturation. Cell Calcium 2007, $42,556-564$. [CrossRef] [PubMed]

72. Mazloomi, S.; Sharifi, F.; Hajihosseini, R.; Kalantari, S.; Mazloomzadeh, S. Association between hypoadiponectinemia and low serum concentrations of calcium and vitamin D in women with polycystic ovary syndrome. ISRN Endocrinol. 2012. [CrossRef] [PubMed]

73. Dehghani Firouzabadi, R.; Aflatoonian, A.; Modarresi, S.; Sekhavat, L.; MohammadTaheri, S. Therapeutic effects of calcium \& vitamin D supplementation in women with PCOS. Complement. Ther. Clin. Pract. 2012, 18, 85-88.

74. Mirone, M.; Giannetta, E.; Isidori, A. Selenium and reproductive function. A systematic review. J. Endocrinol. Invest. 2013, 36, $28-36$.

75. Coskun, A.; Arikan, T.; Kilinc, M.; Arikan, D.C.; Ekerbiçer, H.Ç. Plasma selenium levels in Turkish women with polycystic ovary syndrome. Eur. J. Obstet. Gynecol. Reprod. Biol. 2013, 168, 183-186. [CrossRef]

76. Modarres, S.Z.; Heidar, Z.; Foroozanfard, F.; Rahmati, Z.; Aghadavod, E.; Asemi, Z. The effects of selenium supplementation on gene expression related to insulin and lipid in infertile polycystic ovary syndrome women candidate for in vitro fertilization: A randomized, double-blind, placebo-controlled trial. Biol. Trace Elem. Res. 2018, 183, 218-225. [CrossRef]

77. Jamilian, M.; Razavi, M.; Fakhrie Kashan, Z.; Ghandi, Y.; Bagherian, T.; Asemi, Z. Metabolic response to selenium supplementation in women with polycystic ovary syndrome: A randomized, double-blind, placebo-controlled trial. Clin. Endocrinol. 2015, 82, 885-891. [CrossRef]

78. Tubek, S. Zinc supplementation or regulation of its homeostasis: Advantages and threats. Biol. Trace Elem. Res. 2007, 119, 1-9. [CrossRef]

79. Beletate, V.; el Dib, R.; Atallah, Á.N. Zinc supplementation for the prevention of type 2 diabetes mellitus. Cochrane Datab. Syst. Rev. 2007, 1, CD005525. [CrossRef]

80. Guler, I.; Himmetoglu, O.; Turp, A.; Erdem, A.; Erdem, M.; Onan, M.A.; Taskiran, C.; Taslipinar, M.Y.; Guner, H. Zinc and homocysteine levels in polycystic ovarian syndrome patients with insulin resistance. Biol. Trace Elem. Res. 2014, 158, 297-304. [CrossRef]

81. Saris, N.E.; Mervaala, E.; Karppanen, H.; Khawaja, J.A.; Lewenstam, A. Magnesium: An update on physiological, clinical and analytical aspects. Clin. Chim. Acta 2000, 294, 1-26. [CrossRef]

82. Rumawas, M.E.; McKeown, N.M.; Rogers, G.; Meigs, J.B.; Wilson, P.W.; Jacques, P.F. Magnesium intake is related to improved insulin homeostasis in the framingham offspring cohort. J. Am. Coll. Nutr. 2006, 25, 486-492. [CrossRef]

83. Ryan, L.G.; Syrop, C.H.; van Voorhis, B.J. Role, epidemiology, and natural history of benign uterine mass lesions. Clin. Obstet. Gynecol. 2005, 48, 312-324. [CrossRef]

84. Ulin, M.; Ali, M.; Chaudhry, Z.T.; Al-Hendy, A.; Yang, Q. Uterine fibroids in menopause and perimenopause. Menopause 2020, $27,238-242$. [CrossRef]

85. Wu, J.M.; Wechter, M.E.; Geller, E.J.; Nguyen, T.V.; Visco, A.G. Hysterectomy rates in the United States, 2003. Obstet. Gynecol. 2007, 110, 1091-1095. [CrossRef]

86. Cardozo, E.R.; Clark, A.D.; Banks, N.K.; Henne, M.B.; Stegmann, B.J.; Segars, J.H. The estimated annual cost of uterine leiomyomata in the United States. Am. J. Obstet. Gynecol. 2012, 206, 211e1. [CrossRef] [PubMed]

87. Ciebiera, M.; Ali, M.; Prince, L.; Jackson-Bey, T.; Atabiekov, I.; Zgliczyński, S.; Al-Hendy, A. The Evolving Role of Natural Compounds in the Medical Treatment of Uterine Fibroids. J. Clin. Med. 2020, 9, 1479. [CrossRef]

88. Ali, M.; Esfandyari, S.; Al-Hendy, A. Evolving role of microRNAs in uterine fibroid pathogenesis: Filling the gap! Fertil. Steril. 2020, 113, 1167-1168. [CrossRef]

89. Laughlin, K.S.; Schroeder, J.C.; Baird, D.D. New directions in the epidemiology of uterine fibroids. Semin. Reprod. Med. 2010, $28,204-217$. [CrossRef]

90. Tinelli, A.; Vinciguerra, M.; Malvasi, A.; Andjić, M.; Babović, I.; Sparić, R. Uterine Fibroids and Diet. Int. J. Environ. Res. Publ. Health 2021, 18, 1066. [CrossRef] 
91. Mozaffarian, D.; Pischon, T.; Hankinson, S.E.; Rifai, N.; Joshipura, K.; Willett, W.C.; Rimm, E.B. Dietary intake of trans fatty acids and systemic inflammation in women. Am. J. Clin. Nutr. 2004, 79, 606-612. [CrossRef]

92. Wu, H.A.; Pike, M.C.; Stram, D.O. Meta-analysis: Dietary fat intake, serum estrogen levels, and the risk of breast cancer. J. Natl. Cancer Inst. 1999, 91, 529-534. [CrossRef] [PubMed]

93. Baird, D.D.; Patchel, S.A.; Saldana, T.M.; Umbach, D.M.; Cooper, T.; Wegienka, G.; Harmon, Q.E. Uterine fibroid incidence and growth in an ultrasound-based, prospective study of young African Americans. Am. J. Obstet. Gynecol. 2020, $223,402 \mathrm{e} 1$. [CrossRef] [PubMed]

94. Kristal, R.A.; Shattuck, A.L.; Patterson, R.E. Differences in fat-related dietary patterns between black, Hispanic and White women: Results from the women's health trial feasibility study in minority populations. Pub. Health Nutr. 1999, 2, 253-262. [CrossRef]

95. Rosenberg, L.; Adams-Campbell, L.; Palmer, J.R. The black women's health study: A follow-up study for causes and preventions of illness. J. Am. Med. Wom. Assoc. 1995, 50, 56-58.

96. Wise, L.A.; Radin, R.G.; Kumanyika, S.K.; Ruiz-Narvaez, E.A.; Palmer, J.R.; Rosenberg, L. Prospective study of dietary fat and risk of uterine leiomyomata. Am. J. Clin. Nutr. 2014, 99, 1105-1116. [CrossRef]

97. Brasky, T.M.; Bethea, T.N.; Wesselink, A.K.; Wegienka, G.R.; Baird, D.D.; Wise, L.A. Dietary fat intake and risk of uterine leiomyomata: A prospective ultrasound study. Am. J. Epidemiol. 2020, 189, 1538-1546. [CrossRef]

98. Harris, H.R.; Eliassen, A.H.; Doody, D.R.; Terry, K.L.; Missmer, S.A. Dietary fat intake, erythrocyte fatty acids, and risk of uterine fibroids. Fertil. Steril. 2020, 114, 837-847. [CrossRef] [PubMed]

99. Wegienka, G. Are uterine leiomyoma a consequence of a chronically inflammatory immune system? Med. Hypotheses 2012, 79, 226-231. [CrossRef] [PubMed]

100. Chiaffarino, F.; Parazzini, F.; La Vecchia, C.; Chatenoud, L.; Di Cintio, E.; Marsico, S. Diet. and uterine myomas. Obstet. Gynecol. 1999, 94, 395-398. [PubMed]

101. Nagata, C.; Nakamura, K.; Oba, S.; Hayashi, M.; Takeda, N.; Yasuda, K. Association of intakes of fat, dietary fibre, soya isoflavones and alcohol with uterine fibroids in Japanese women. Br. J. Nutr. 2009, 101, 1427-1431. [CrossRef] [PubMed]

102. Islam, M.S.; Castellucci, C.; Fiorini, R.; Greco, S.; Gagliardi, R.; Zannotti, A.; Giannubilo, S.R.; Ciavattini, A.; Frega, N.G.; Pacetti, D.; et al. Omega-3 fatty acids modulate the lipid profile, membrane architecture, and gene expression of leiomyoma cells. J. Cell. Physiol. 2018, 233, 7143-7156. [CrossRef] [PubMed]

103. Kant, K.A.; Graubard, B.I. Ethnicity is an independent correlate of biomarkers of micronutrient intake and status in American adults. J. Nutr. 2007, 137, 2456-2463. [CrossRef] [PubMed]

104. Timbo, B.B.; Ross, M.P.; McCarthy, P.V.; Lin, C.T. Dietary supplements in a national survey: Prevalence of use and reports of adverse events. J. Am. Diet. Assoc. 2006, 106, 1966-1974. [CrossRef] [PubMed]

105. Wise, L.A.; Radin, R.G.; Palmer, J.R.; Kumanyika, S.K.; Boggs, D.A.; Rosenberg, L. Intake of fruit, vegetables, and carotenoids in relation to risk of uterine leiomyomata. Am. J. Clin. Nutr. 2011, 94, 1620-1631. [CrossRef] [PubMed]

106. He, Y.; Zeng, Q.; Dong, S.; Qin, L.; Li, G.; Wang, P. Associations between uterine fibroids and lifestyles including diet, physical activity and stress: A case-control study in China. Asia Pac. J. Clin. Nutr. 2013, 22, 109-117. [PubMed]

107. Sahin, K.; Ozercan, R.; Onderci, M.; Sahin, N.; Gursu, M.F.; Khachik, F.; Sarkar, F.H.; Munkarah, A.; Ali-Fehmi, R.; Kmak, D.; et al. Lycopene supplementation prevents the development of spontaneous smooth muscle tumors of the oviduct in Japanese quail. Nutr. Cancer 2004, 50, 181-189. [CrossRef] [PubMed]

108. Setchell, K.D.; Cassidy, A. Dietary isoflavones: Biological effects and relevance to human health. J. Nutr. 1999, 129, 758S-767S. [CrossRef] [PubMed]

109. Greco, S.; Islam, M.S.; Zannotti, A.; Carpini, G.D.; Giannubilo, S.R.; Ciavattini, A.; Petraglia, F.; Ciarmela, P. Quercetin and indole-3-carbinol inhibit extracellular matrix expression in human primary uterine leiomyoma cells. Reprod. Biomed. Online 2020, 40, 593-602. [CrossRef]

110. Lila, M.A.; Burton-Freeman, B.; Grace, M.; Kalt, W. Unraveling Anthocyanin Bioavailability for Human Health. Annu. Rev. Food Sci. Technol. 2016, 7, 375-393. [CrossRef] [PubMed]

111. Wang, S.Y.; Feng, R.; Lu, Y.; Bowman, L.; Ding, M. Inhibitory effect on activator protein-1, nuclear factor-kappaB, and cell transformation by extracts of strawberries (Fragaria x ananassa Duch.). J. Agric. Food Chem. 2005, 53, 4187-4193. [CrossRef]

112. Giampieri, F.; Islam, M.S.; Greco, S.; Gasparrini, M.; Forbes Hernandez, T.Y.; Delli Carpini, G.; Giannubilo, S.R.; Ciavattini, A.; Mezzetti, B.; Capocasa, F.; et al. Romina: A powerful strawberry with in vitro efficacy against uterine leiomyoma cells. J. Cell. Physiol. 2019, 234, 7622-7633. [CrossRef] [PubMed]

113. Islam, M.S.; Giampieri, F.; Janjusevic, M.; Gasparrini, M.; Forbes-Hernandez, T.Y.; Mazzoni, L.; Greco, S.; Giannubilo, S.R.; Ciavattini, A.; Mezzetti, B.; et al. Anthocyanin rich strawberry extract induces apoptosis and ROS while decreases glycolysis and fibrosis in human uterine leiomyoma cells. Oncotarget 2017, 8, 23575-23587. [CrossRef] [PubMed]

114. Kim, D.C.; Ramachandran, S.; Baek, S.H.; Kwon, S.H.; Kwon, K.Y.; Cha, S.D.; Bae, I.; Cho, C.H. Induction of growth inhibition and apoptosis in human uterine leiomyoma cells by isoliquiritigenin. Reprod. Sci. 2008, 15, 552-558. [CrossRef]

115. Moore, A.B.; Castro, L.; Yu, L.; Zheng, X.; Di, X.; Sifre, M.I.; Kissling, G.E.; Newbold, R.R.; Bortner, C.D.; Dixon, D. Stimulatory and inhibitory effects of genistein on human uterine leiomyoma cell proliferation are influenced by the concentration. Hum. Reprod. 2007, 22, 2623-2631. [CrossRef] [PubMed] 
116. Di, X.; Yu, L.; Moore, A.B.; Castro, L.; Zheng, X.; Hermon, T.; Dixon, D. A low concentration of genistein induces estrogen receptor-alpha and insulin-like growth factor-I receptor interactions and proliferation in uterine leiomyoma cells. Hum. Reprod. 2008, 23, 1873-1883. [CrossRef]

117. Beydoun, M.A.; Gary, T.L.; Caballero, B.H.; Lawrence, R.S.; Cheskin, L.J.; Wang, Y. Ethnic differences in dairy and related nutrient consumption among US adults and their association with obesity, central obesity, and the metabolic syndrome. Am. J. Clin. Nutr. 2008, 87, 1914-1925. [CrossRef]

118. Lu, W.; Chen, H.; Niu, Y.; Wu, H.; Xia, D.; Wu, Y. Dairy products intake and cancer mortality risk: A meta-analysis of 11 population-based cohort studies. Nutr. J. 2016, 15, 91. [CrossRef]

119. Shen, Y.; Xu, Q.; Xu, J.; Ren, M.L.; Cai, Y.L. Environmental exposure and risk of uterine leiomyoma: An epidemiologic survey. Eur. Rev. Med. Pharmacol. Sci. 2013, 17, 3249-3256.

120. Wise, L.A.; Radin, R.G.; Palmer, J.R.; Kumanyika, S.K.; Rosenberg, L. A prospective study of dairy intake and risk of uterine leiomyomata. Am. J. Epidemiol. 2010, 171, 221-232. [CrossRef]

121. Wise, L.A.; Ruiz-Narváez, E.A.; Haddad, S.A.; Rosenberg, L.; Palmer, J.R. Polymorphisms in vitamin D-related genes and risk of uterine leiomyomata. Fertil. Steril. 2014, 102, 503-510.e1. [CrossRef]

122. Ciebiera, M.; Ali, M.; Prince, L.; Zgliczyński, S.; Jakiel, G.; Al-Hendy, A. The Significance of Measuring Vitamin D Serum Levels in Women with Uterine Fibroids. Reprod. Sci. 2020. [CrossRef]

123. Al-Hendy, A.; Diamond, M.P.; El-Sohemy, A.; Halder, S.K. 1,25-dihydroxyvitamin D3 regulates expression of sex steroid receptors in human uterine fibroid cells. J. Clin. Endocrinol. Metab. 2015, 100, E572-E582. [CrossRef]

124. Ciebiera, M.; Ali, M.; Zgliczyńska, M.; Skrzypczak, M.; Al-Hendy, A. Vitamins and uterine fibroids: Current data on pathophysiology and possible clinical relevance. Int. J. Mol. Sci. 2020, 21, 5528. [CrossRef]

125. Ali, M.; Al-Hendy, A.; Yang, Q. Vitamin D, a promising natural compound with anti-uterine fibroid characteristics. Fertil. Steril. 2019, 111, 268-269. [CrossRef]

126. Elkafas, H.; Ali, M.; Elmorsy, E.; Kamel, R.; Thompson, W.E.; Badary, O.; Al-Hendy, A.; Yang, Q. Vitamin d3 ameliorates dna damage caused by developmental exposure to endocrine disruptors in the uterine myometrial stem cells of Eker rats. Cells 2020, 9, 1459. [CrossRef]

127. Ali, M.; Shahin, S.M.; Sabri, N.A.; Al-Hendy, A.; Yang, Q. Hypovitaminosis D exacerbates the DNA damage load in human uterine fibroids, which is ameliorated by vitamin D3 treatment. Acta Pharmacol. Sin. 2019, 40, 957-970. [CrossRef]

128. ElHusseini, H.; Elkafas, H.; Abdelaziz, M.; Halder, S.; Atabiekov, I.; Eziba, N.; Ismail, N.; El Andaloussi, A.; Al-Hendy, A. Diet.-induced vitamin D deficiency triggers inflammation and DNA damage profile in murine myometrium. Int. J. Women's Health 2018, 10, 503-514. [CrossRef] [PubMed]

129. Sheng, B.; Song, Y.; Liu, Y.; Jiang, C.; Zhu, X. Association between vitamin D and uterine fibroids: A study protocol of an open-label, randomised controlled trial. BMJ Open 2020, 10, e038709. [CrossRef] [PubMed]

130. Prins, G.S.; Hu, W.Y.; Shi, G.B.; Hu, D.P.; Majumdar, S.; Li, G.; Huang, K.; Nelles, J.L.; Ho, S.M.; Walker, C.L.; et al. Bisphenol A promotes human prostate stem-progenitor cell self-renewal and increases in vivo carcinogenesis in human prostate epithelium. Endocrinology 2014, 155, 805-817. [CrossRef] [PubMed]

131. Bariani, M.V.; Rangaswamy, R.; Siblini, H.; Yang, Q.; Al-Hendy, A.; Zota, A.R. The role of endocrine-disrupting chemicals in uterine fibroid pathogenesis. Curr. Opin. Endocrinol. Diabetes Obes. 2020, 27, 380-387. [CrossRef] [PubMed]

132. Johnstone, E.B.; Louis, G.M.; Parsons, P.J.; Steuerwald, A.J.; Palmer, C.D.; Chen, Z.; Sun, L.; Hammoud, A.O.; Dorais, J.; Peterson, C.M. Increased urinary cobalt and whole blood concentrations of cadmium and lead in women with uterine leiomyomata: Findings from the ENDO Study. Reprod. Toxicol. 2014, 49, 27-32. [CrossRef] [PubMed]

133. Jackson, L.W.; Zullo, M.D.; Goldberg, J.M. The association between heavy metals, endometriosis and uterine myomas among premenopausal women: National Health and Nutrition Examination Survey 1999-2002. Hum. Reprod. 2008, 23, 679-687. [CrossRef] [PubMed]

134. Maybin, J.A.; Critchley, H.O. Menstrual physiology: Implications for endometrial pathology and beyond. Hum. Reprod. Update 2015, 21, 748-761. [CrossRef]

135. Karamian, A.; Paktinat, S.; Esfandyari, S.; Nazarian, H.; Ali Ziai, S.; Zarnani, A.H.; Salehpour, S.; Hosseinirad, H.; Karamian, A.; Novin, M.G. Pyrvinium pamoate induces in-vitro suppression of IL-6 and IL-8 produced by human endometriotic stromal cells. Hum. Exp. Toxicol. 2020, 4, 649-660.

136. Nnoaham, K.E.; Hummelshoj, L.; Webster, P.; d'Hooghe, T.; de Cicco Nardone, F.; de Cicco Nardone, C.; Jenkinson, C.; Kennedy, S.H.; Zondervan, K.T.; Study, W.E. Impact of endometriosis on quality of life and work productivity: A multicenter study across ten countries. Fertil. Steril. 2011, 96, 366-373e8. [CrossRef]

137. Taylor, R.N.; Lebovic, D.I.; Mueller, M.D. Angiogenic factors in endometriosis. Ann. N. Y. Acad. Sci. USA 2002, 955, 89-100. [CrossRef]

138. Husby, G.K.; Haugen, R.S.; Moen, M.H. Diagnostic delay in women with pain and endometriosis. Acta Obstet. Gynecol. Scand. 2003, 82, 649-653. [CrossRef] [PubMed]

139. Sourial, S.; Tempest, N.; Hapangama, D.K. Theories on the pathogenesis of endometriosis. Int. J. Reprod. Med. 2014, $2014,179515$. [CrossRef]

140. Youseflu, S.; Jahanian Sadatmahalleh, S.; Mottaghi, A.; Kazemnejad, A. The association of food consumption and nutrient intake with endometriosis risk in Iranian women: A case-control study. Int. J. Reprod. BioMed. 2019, 17, 661. 
141. Aris, A.; Paris, K. Hypothetical link between endometriosis and xenobiotics-associated genetically modified food. Gynecol. Obstet. Fertil. 2010, 38, 747-753.

142. Khanaki, K.; Nouri, M.; Ardekani, A.M.; Ghassemzadeh, A.; Shahnazi, V.; Sadeghi, M.R.; Darabi, M.; Mehdizadeh, A.; Dolatkhah, H.; Saremi, A.; et al. Evaluation of the relationship between endometriosis and omega-3 and omega-6 polyunsaturated fatty acids. Iran. Biomed. J. 2012, 16, 38.

143. Halpern, G.; Schor, E.; Kopelman, A. Nutritional aspects related to endometriosis. Rev. Assoc. Méd. Brasil. 2015, 61, 519-523. [CrossRef]

144. Lasco, A.; Catalano, A.; Benvenga, S. Improvement of primary dysmenorrhea caused by a single oral dose of vitamin D: Results of a randomized, double-blind, placebo-controlled study. Arch. Intern. Med. 2012, 172, 366-367. [CrossRef] [PubMed]

145. Almassinokiani, F.; Khodaverdi, S.; Solaymani-Dodaran, M.; Akbari, P.; Pazouki, A. Effects of vitamin D on endometriosis-related pain: A double-blind clinical trial. Med. Sci. Monit. Int. Med. J. Exper. Clin. Res. 2016, 22, 4960. [CrossRef] [PubMed]

146. Ngô, C.; Chéreau, C.; Nicco, C.; Weill, B.; Chapron, C.; Batteux, F. Reactive oxygen species controls endometriosis progression. Am. J. Pathol. 2009, 175, 225-234. [CrossRef] [PubMed]

147. Porpora, M.G.; Brunelli, R.; Costa, G.; Imperiale, L.; Krasnowska, E.K.; Lundeberg, T.; Nofroni, I.; Piccioni, M.G.; Pittaluga, E.; Ticino, A.; et al. A promise in the treatment of endometriosis: An observational cohort study on ovarian endometrioma reduction by N-acetylcysteine. Evid. Based Complement. Altern. Med. 2013, 2013, 240702. [CrossRef] [PubMed]

148. Park, S.; Lim, W.; Bazer, F.W.; Whang, K.Y.; Song, G. Quercetin inhibits proliferation of endometriosis regulating cyclin D1 and its target microRNAs in vitro and in vivo. J. Nutr. Biochem. 2019, 63, 87-100. [CrossRef] [PubMed]

149. Cao, Y.; Zhuang, M.F.; Yang, Y.; Xie, S.W.; Cui, J.G.; Cao, L.; Zhang, T.T.; Zhu, Y. Preliminary study of quercetin affecting the hypothalamic-pituitary-gonadal axis on rat endometriosis model. Evid. Based Complement. Altern. Med. 2014, $2014,781684$. [CrossRef] [PubMed]

150. Ergenoğlu, A.M.; Yeniel, A.Ö.; Erbaş, O.; Aktuğ, H.; Yildirim, N.; Ulukuş, M.; Taskiran, D. Regression of endometrial implants by resveratrol in an experimentally induced endometriosis model in rats. Reprod. Sci. 2013, 20, 1230-1236. [CrossRef]

151. Khodarahmian, M.; Amidi, F.; Moini, A.; Kashani, L.; Salahi, E.; Danaii-Mehrabad, S.; Nashtaei, M.S.; Mojtahedi, M.F.; Esfandyari, S.; Sobhani, A. A randomized exploratory trial to assess the effects of resveratrol on VEGF and TNF- $\alpha 2$ expression in endometriosis women. J. Reprod. Immunol. 2020, 143, 103248. [CrossRef]

152. Zhou, A.; Hong, Y.; Lv, Y. Sulforaphane attenuates endometriosis in rat models through inhibiting pi3k/akt signaling pathway. Dose Res. 2019, 17, 1559325819855538. [CrossRef]

153. Valipour, J.; Nashtaei, M.S.; Khosravizadeh, Z.; Mahdavinezhad, F.; Nekoonam, S.; Esfandyari, S.; Amidi, F. Effect of sulforaphane on apoptosis, reactive oxygen species and lipids peroxidation of human sperm during cryopreservation. Cryobiology 2021, 99, 122-130. [CrossRef]

154. Stephens, F.B.; Constantin-Teodosiu, D.; Greenhaff, P.L. New insights concerning the role of carnitine in the regulation of fuel metabolism in skeletal muscle. J. Pshycol. 2007, 581, 431-444. [CrossRef]

155. Tselekidou, E.D.; Vassiliadis, S.; Athanassakis, I. Establishment or Aggravation of Endometriosis by L-Carnitine: The Role of Pge1 and Pge2 in the Endometriosis-Induction Process. New Developments in Endometriosis. Available online: https: / / www.createspace.com (accessed on 15 January 2021).

156. Gerbase, A.C.; Rowley, J.T.; Heymann, D.H.; Berkley, S.F.; Piot, P. Global prevalence and incidence estimates of selected curable STDs. Sex Transm. Infect. 1998, 74, S12-S16.

157. Onisto, M.; Fasolato, S.; Veggian, R.; Caenazzo, C.; Garbisa, S. Hormonal and basement membrane markers for immunoidentification of cultured human trophoblast cells. Int. J. Gynaecol. Obstet. 1989, 30, 145-153. [CrossRef]

158. Rabiu, K.A.; Adewunmi, A.A.; Akinlusi, F.M.; Akinola, O.I. Female reproductive tract infections: Understandings and care seeking behaviour among women of reproductive age in Lagos, Nigeria. BMC Women's Health. 2010, 10, 8. [CrossRef]

159. Moreno, I.; Simon, C. Relevance of assessing the uterine microbiota in infertility. Fertil. Steril. 2018, 110, 337-343. [CrossRef]

160. Heil, B.A.; Paccamonti, D.L.; Sones, J.L. Role for the mammalian female reproductive tract microbiome in pregnancy outcomes. Physiol. Genomics 2019, 51, 390-399. [CrossRef]

161. Krawinkel, M.B. Interaction of nutrition and infections globally: An overview. Ann. Nutr. Metab. 2012, 61, 39-45. [CrossRef]

162. Cassotta, M.; Forbes-Hernández, T.Y.; Calderón Iglesias, R.; Ruiz, R.; Elexpuru Zabaleta, M.; Giampieri, F.; Battino, M. Links between nutrition, infectious diseases, and microbiota: Emerging technologies and opportunities for human-focused research. Nutrients 2020, 12, 1827. [CrossRef]

163. Molenaar, M.C.; Singer, M.; Ouburg, S. The two-sided role of the vaginal microbiome in Chlamydia trachomatis and Mycoplasma genitalium pathogenesis. J. Reprod. Immunol. 2018, 130, 11-17. [CrossRef]

164. Tuddenham, S.; Ghanem, K.G. A microbiome variable in the HIV-prevention equation. Science 2017, 356, 907-908. [CrossRef]

165. Martin, D.H.; Marrazzo, J.M. The vaginal microbiome: Current understanding and future directions. J. Infect. Dis. 2016, 214, S36-S41. [CrossRef]

166. Borgogna, J.L.; Shardell, M.D.; Yeoman, C.J.; Ghanem, K.G.; Kadriu, H.; Ulanov, A.V.; Gaydos, C.A.; Hardick, J.; Robinson, C.K.; Bavoil, P.M.; et al. The association of Chlamydia trachomatis and Mycoplasma genitalium infection with the vaginal metabolome. Sci. Rep. 2020, 10, 3420. [CrossRef] 
167. Ng, K.Y.; Mingels, R.; Morgan, H.; Macklon, N.; Cheong, Y. In vivo oxygen, temperature and pH dynamics in the female reproductive tract and their importance in human conception: A systematic review. Hum. Reprod. Update 2018, 24, 15-34. [CrossRef]

168. Van Oostrum, N.; De Sutter, P.; Meys, J.; Verstraelen, H. Risks associated with bacterial vaginosis in infertility patients: A systematic review and meta-analysis. Hum. Reprod. 2013, 28, 1809-1815. [CrossRef]

169. Koumans, E.H.; Sternberg, M.; Bruce, C.; McQuillan, G.; Kendrick, J.; Sutton, M.; Markowitz, L.E. The prevalence of bacterial vaginosis in the United States, 2001-2004; associations with symptoms, sexual behaviors, and reproductive health. Sex. Transm. Dis. 2007, 34, 864-869. [CrossRef] [PubMed]

170. Thoma, M.E.; Klebanoff, M.A.; Rovner, A.J.; Nansel, T.R.; Neggers, Y.; Andrews, W.W.; Schwebke, J.R. Bacterial vaginosis is associated with variation in dietary indices. J. Nutr. 2011, 141, 1698-1704. [CrossRef] [PubMed]

171. Smart, S.; Singal, A.; Mindel, A. Social and sexual risk factors for bacterial vaginosis. Sex. Transm. Infect. 2004, 80, 58-62. [CrossRef] [PubMed]

172. Neggers, Y.H.; Nansel, T.R.; Andrews, W.W.; Schwebke, J.R.; Yu, K.F.; Goldenberg, R.L.; Klebanoff, M.A. Dietary intake of selected nutrients affects bacterial vaginosis in women. J. Nutr. 2007, 137, 2128-2133. [CrossRef]

173. Bodnar, L.M.; Krohn, M.A.; Simhan, H.N. Maternal vitamin D deficiency is associated with bacterial vaginosis in the first trimester of pregnancy. J. Nutr. 2009, 139, 1157-1161. [CrossRef]

174. Mitchell, C.; Marrazzo, J. Bacterial vaginosis and the cervicovaginal immune response. Am. J. Reprod. Immunol. 2014, 71, 555-563. [CrossRef] [PubMed]

175. Dunlop, A.L.; Taylor, R.N.; Tangpricha, V.; Fortunato, S.; Menon, R. Maternal vitamin D, folate, and polyunsaturated fatty acid status and bacterial vaginosis during pregnancy. Infect. Dis. Obstet. Gynecol. 2011, 2011, 216217. [CrossRef]

176. Hensel, K.J.; Randis, T.M.; Gelber, S.E.; Ratner, A.J. Pregnancy-specific association of vitamin D deficiency and bacterial vaginosis. Am. J. Obstet. Gynecol. 2011, 204, 41-e1. [CrossRef]

177. Taheri, M.; Baheiraei, A.; Foroushani, A.R.; Nikmanesh, B.; Modarres, M. Treatment of vitamin D deficiency is an effective method in the elimination of asymptomatic bacterial vaginosis: A placebo-controlled randomized clinical trial. Indian J. Med. Res. 2015, 141, 799-806.

178. Al-Ghazzewi, F.H.; Tester, R.F. Biotherapeutic agents and vaginal health. J. Appl. Microbiol. 2016, 121, 18-27. [CrossRef]

179. Tuominen, H.; Rautava, S.; Syrjänen, S.; Collado, M.C.; Rautava, J. HPV infection and bacterial microbiota in the placenta, uterine cervix and oral mucosa. Sci. Rep. 2018, 8, 9787. [CrossRef]

180. Atashili, J.; Poole, C.; Ndumbe, P.M.; Adimora, A.A.; Smith, J.S. Bacterial vaginosis and HIV acquisition: A meta-analysis of published studies. AIDS 2008, 22, 1493-1501. [CrossRef]

181. Allsworth, J.E.; Lewis, V.A.; Peipert, J.F. Viral sexually transmitted infections and bacterial vaginosis: 2001-2004 national health and nutrition examination survey data. Sex. Transm. Dis. 2008, 35, 791-796. [CrossRef]

182. White, M.C.; Hayes, N.S.; Richardson, L.C. Public health's future role in cancer survivorship. Am. J. Prev. Med. 2015, 49, S550-S553. [CrossRef]

183. Dunn, B.K.; Kramer, B.S. Cancer prevention: Lessons learned and future directions. Trends Cancer 2016, 2, 713-722. [CrossRef] [PubMed]

184. Sundstrom, K.; Elfstrom, K.M. Advances in cervical cancer prevention: Efficacy, effectiveness, elimination? PLoS MED 2020, 17 , e1003035. [CrossRef]

185. MacKintosh, M.L.; Crosbie, E.J. Prevention strategies in endometrial carcinoma. Curr. Oncol. Rep. 2018, 20, 101. [CrossRef]

186. Temkin, S.M.; Bergstrom, J.; Samimi, G.; Minasian, L. Ovarian cancer prevention in high.-risk women. Clin. Obstet. Gynecol. 2017, 60, 738-757. [CrossRef]

187. Szewczuk, M.; Gasiorowska, E.; Matysiak, K.; Nowak-Markwitz, E. The role of artificial nutrition in gynecological cancer therapy. Ginekol. Pol. 2019, 90, 167-172. [CrossRef]

188. Koshiyama, M. The effects of the dietary and nutrient intake on gynecologic cancers. Healthcare 2019, 7, 88. [CrossRef]

189. Key, T.J.; Bradbury, K.E.; Perez-Cornago, A.; Sinha, R.; Tsilidis, K.K.; Tsugane, S. Diet, nutrition, and cancer risk: What do we know and what is the way forward? BMJ 2020, 368, 368. [CrossRef]

190. Ferenczy, A.; Franco, E. Persistent human papillomavirus infection and cervical neoplasia. Lancet Oncol. 2002, 3, 11-16. [CrossRef]

191. Stebbing, J.; Hart, C.A. Antioxidants and cancer. Lancet Oncol. 2011, 12, 996. [CrossRef]

192. Tomita, L.Y.; Roteli-Martins, C.M.; Villa, L.L.; Franco, E.L.; Cardoso, M.A. Associations of dietary dark-green and deep-yellow vegetables and fruits with cervical intraepithelial neoplasia: Modification by smoking. Br. J. Nutr. 2011, 105, 928-937. [CrossRef] [PubMed]

193. Siegel, E.M.; Salemi, J.L.; Villa, L.L.; Ferenczy, A.; Franco, E.L.; Giuliano, A.R. Dietary consumption of antioxidant nutrients and risk of incident cervical intraepithelial neoplasia. Gynecol. Oncol. 2010, 118, 289-294. [CrossRef]

194. Jia, Y.; Hu, T.; Hang, C.Y.; Yang, R.; Li, X.; Chen, Z.L.; Mei, Y.D.; Zhang, Q.H.; Huang, K.C.; Xiang, Q.Y.; et al. Case-control study of diet in patients with cervical cancer or precancerosis in Wufeng, a high incidence region in China. Asian Pac. J. Cancer Prev. 2012, 13, 5299-5302. [CrossRef] [PubMed]

195. Guo, L.; Zhu, H.; Lin, C.; Che, J.; Tian, X.; Han, S.; Zhao, H.; Zhu, Y.; Mao, D. Associations between antioxidant vitamins and the risk of invasive cervical cancer in Chinese women: A case-control study. Sci. Rep. 2015, 5, 13607. [CrossRef] 
196. Giuliano, A.R.; Siegel, E.M.; Roe, D.J.; Ferreira, S.; Luiza Baggio, M.; Galan, L.; Duarte-Franco, E.; Villa, L.L.; Rohan, T.E.; Marshall, J.R.; et al. Dietary intake and risk of persistent human papillomavirus (HPV) infection: The Ludwig-McGill HPV natural history study. J. Infect. Dis. 2003, 188, 1508-1516. [CrossRef]

197. Ono, A.; Koshiyama, M.; Nakagawa, M.; Watanabe, Y.; Ikuta, E.; Seki, K.; Oowaki, M. The preventive effect of dietary antioxidants on cervical cancer development. Medicina 2020, 56, 604. [CrossRef]

198. Yeo, A.S.; Schiff, M.A.; Montoya, G.; Masuk, M.; van Asselt-King, L.; Becker, T.M. Serum micronutrients and cervical dysplasia in Southwestern American Indian women. Nutr. Cancer 2000, 38, 141-150. [CrossRef]

199. Huang, X.; Chen, C.; Zhu, F.; Zhang, Y.; Feng, Q.; Li, J.; Yu, Q.; Zhong, Y.; Luo, S.; Gao, J. Association between dietary vitamin A and HPV infection in American women: Data from NHANES 2003-2016. Biomed Res. Int. 2020, 2020, 4317610. [CrossRef] [PubMed]

200. Rizvi, S.; Raza, S.T.; Faizal Ahmed, A.A.; Abbas, S.; Mahdi, F. The role of vitamin e in human health and some diseases. Sultan Qaboos Univ. Med. J. 2014, 14, e157-e165. [PubMed]

201. Hu, X.; Li, S.; Zhou, L.; Zhao, M.; Zhu, X. Effect of vitamin E supplementation on uterine cervical neoplasm: A meta-analysis of case-control studies. PLoS ONE 2017, 12, e0183395. [CrossRef]

202. Vahedpoor, Z.; Jamilian, M.; Bahmani, F.; Aghadavod, E.; Karamali, M.; Kashanian, M.; Asemi, Z. Effects of long-term vitamin d supplementation on regression and metabolic status of cervical intraepithelial neoplasia: A randomized, double-blind, placebocontrolled trial. Horm. Cancer 2017, 8, 58-67. [CrossRef]

203. Hernandez, B.Y.; McDuffie, K.; Wilkens, L.R.; Kamemoto, L.; Goodman, M.T. Diet. and premalignant lesions of the cervix: Evidence of a protective role for folate, riboflavin, thiamin, and vitamin B12. Cancer Causes Control 2003, 14, 859-870. [CrossRef] [PubMed]

204. Zoberi, I.; Bradbury, C.M.; Curry, H.A.; Bisht, K.S.; Goswami, P.C.; Roti, J.L.; Gius, D. Radiosensitizing and anti-proliferative effects of resveratrol in two human cervical tumor cell lines. Cancer Lett. 2002, 175, 165-173. [CrossRef]

205. Silva, G.Á.; Nunes, R.A.; Morale, M.G.; Boccardo, E.; Aguayo, F.; Termini, L. Oxidative stress: Therapeutic approaches for cervical cancer treatment. Clinics 2018, 73, e548s. [CrossRef] [PubMed]

206. Venkatraman, M.; Anto, R.J.; Nair, A.; Varghese, M.; Karunagaran, D. Biological and chemical inhibitors of NF-kappaB sensitize SiHa cells to cisplatin-induced apoptosis. Mol. Carcinog. 2005, 44, 51-59. [CrossRef]

207. Ciebiera, M.; Łukaszuk, K.; Męczekalski, B.; Ciebiera, M.; Wojtyła, C.; Słabuszewska-Jóźwiak, A.; Jakiel, G. Alternative oral agents in prophylaxis and therapy of uterine fibroids-an up-to-date review. Int. J. Mol. Sci. 2017, 18, 2586. [CrossRef] [PubMed]

208. Min, K.J.; Kwon, T.K. Anticancer effects and molecular mechanisms of epigallocatechin-3-gallate. Integr. Med. Res. 2014, 3, 16-24. [CrossRef] [PubMed]

209. Pennant, M.E.; Mehta, R.; Moody, P.; Hackett, G.; Prentice, A.; Sharp, S.J.; Lakshman, R. Premenopausal abnormal uterine bleeding and risk of endometrial cancer. BJOG 2017, 124, 404-411. [CrossRef]

210. Setiawan, V.W.; Yang, H.P.; Pike, M.C.; McCann, S.E.; Yu, H.; Xiang, Y.B.; Wolk, A.; Wentzensen, N.; Weiss, N.S.; Webb, P.M.; et al. Type I and II endometrial cancers: Have they different risk factors? J. Clin. Oncol. 2013, 31, 2607-2618. [CrossRef]

211. Morice, P.; Leary, A.; Creutzberg, C.; Abu-Rustum, N.; Darai, E. Endometrial cancer. Lancet 2016, 387, 1094-1108. [CrossRef]

212. Leslie, K.K.; Thiel, K.W.; Goodheart, M.J.; De Geest, K.; Jia, Y.; Yang, S. Endometrial cancer. Obstet. Gynecol. Clin. N. Am. 2012, 39, 255-268. [CrossRef]

213. Bandera, E.V.; Gifkins, D.M.; Moore, D.F.; McCullough, M.L.; Kushi, L.H. Antioxidant vitamins and the risk of endometrial cancer: A dose-response meta-analysis. Cancer Causes Control 2009, 20, 699-711. [CrossRef]

214. Cui, X.; Rosner, B.; Willett, W.C.; Hankinson, S.E. Antioxidant intake and risk of endometrial cancer: Results from the Nurses' Health Study. Int. J. Cancer 2011, 128, 1169-1178. [CrossRef]

215. Acmaz, G.; Aksoy, H.; Albayrak, E.; Baser, M.; Ozyurt, S.; Aksoy, U.; Unal, D. Evaluation of endometrial precancerous lesions in postmenopausal obese women-A high risk group? Asian Pac. J. Cancer Prev. 2014, 15, 195-198. [CrossRef] [PubMed]

216. Brasky, T.M.; Neuhouser, M.L.; Cohn, D.E.; White, E. Associations of long-chain omega-3 fatty acids and fish intake with endometrial cancer risk in the VITamins and Lifestyle cohort. Am. J. Clin. Nutr. 2014, 99, 599-608. [CrossRef] [PubMed]

217. Rinaldi, S.; Peeters, P.H.; Bezemer, I.D.; Dossus, L.; Biessy, C.; Sacerdote, C.; Berrino, F.; Panico, S.; Palli, D.; Tumino, R.; et al. Relationship of alcohol intake and sex steroid concentrations in blood in pre- and post-menopausal women: The European prospective investigation into cancer and nutrition. Cancer Causes Control 2006, 17, 1033-1043. [CrossRef] [PubMed]

218. Fedirko, V.; Jenab, M.; Rinaldi, S.; Biessy, C.; Allen, N.E.; Dossus, L.; Onland-Moret, N.C.; Schütze, M.; Tjønneland, A.; Hansen, L.; et al. Alcohol drinking and endometrial cancer risk in the European Prospective Investigation into cancer and nutrition (EPIC) study. Ann. Epidemiol. 2013, 23, 93-98. [CrossRef] [PubMed]

219. Rossi, M.; Edefonti, V.; Parpinel, M.; Lagiou, P.; Franchi, M.; Ferraroni, M.; Decarli, A.; Zucchetto, A.; Serraino, D.; Dal Maso, L.; et al. Proanthocyanidins and other flavonoids in relation to endometrial cancer risk: A case-control study in Italy. Br. J. Cancer 2013, 109, 1914-1920. [CrossRef] [PubMed]

220. Messina, M.J.; Persky, V.; Setchell, K.D.; Barnes, S. Soy intake and cancer risk: A review of the in vitro and in vivo data. Nutr. Cancer 1994, 21, 113-131. [CrossRef]

221. Wang, L.; Lee, I.M.; Zhang, S.M.; Blumberg, J.B.; Buring, J.E.; Sesso, H.D. Dietary intake of selected flavonols, flavones, and flavonoid-rich foods and risk of cancer in middle-aged and older women. Am. J. Clin. Nutr. 2009, 89, 905-912. [CrossRef] 
222. Bandera, E.V.; Williams, M.G.; Sima, C.; Bayuga, S.; Pulick, K.; Wilcox, H.; Soslow, R.; Zauber, A.G.; Olson, S.H. Phytoestrogen consumption and endometrial cancer risk: A population-based case-control study in New Jersey. Cancer Causes Control 2009, 20, 1117-1127. [CrossRef]

223. Ollberding, N.J.; Lim, U.; Wilkens, L.R.; Setiawan, V.W.; Shvetsov, Y.B.; Henderson, B.E.; Kolonel, L.N.; Goodman, M.T. Legume, soy, tofu, and isoflavone intake and endometrial cancer risk in postmenopausal women in the multiethnic cohort study. J. Natl. Cancer Inst. 2012, 104, 67-76. [CrossRef]

224. Zhang, G.Q.; Chen, J.L.; Liu, Q.; Zhang, Y.; Zeng, H.; Zhao, Y. Soy intake is associated with lower endometrial cancer risk: A systematic review and meta-analysis of observational studies. Medicine 2015, 94, e2281. [CrossRef]

225. Zhong, X.S.; Ge, J.; Chen, S.W.; Xiong, Y.Q.; Ma, S.J.; Chen, Q. Association between dietary isoflavones in soy and legumes and endometrial cancer: A systematic review and meta-analysis. J. Acad. Nutr. Diet. 2018, 118, 637-651. [CrossRef] [PubMed]

226. Unfer, V.; Casini, M.L.; Costabile, L.; Mignosa, M.; Gerli, S.; Di Renzo, G.C. Endometrial effects of long-term treatment with phytoestrogens: A randomized, double-blind, placebo-controlled study. Fertil. Steril. 2004, 82, 145-148. [CrossRef] [PubMed]

227. Mohr, S.B.; Garland, C.F.; Gorham, E.D.; Grant, W.B.; Garland, F.C. Is ultraviolet B irradiance inversely associated with incidence rates of endometrial cancer: An ecological study of 107 countries. Prev. Med. 2007, 45, 327-331. [CrossRef]

228. McCullough, M.L.; Bandera, E.V.; Moore, D.F.; Kushi, L.H. Vitamin D and calcium intake in relation to risk of endometrial cancer: A systematic review of the literature. Prev. Med. 2008, 46, 298-302. [CrossRef] [PubMed]

229. Luo, H.; Rankin, G.O.; Li, Z.; DePriest, L.; Chen, Y.C. Kaempferol induces apoptosis in ovarian cancer cells through activating p53 in the intrinsic pathway. Food Chem. 2011, 128, 513-519. [CrossRef] [PubMed]

230. Chuwa, A.H.; Sone, K.; Oda, K.; Tanikawa, M.; Kukita, A.; Kojima, M.; Oki, S.; Fukuda, T.; Takeuchi, M.; Miyasaka, A.; et al. Kaempferol, a natural dietary flavonoid, suppresses 17beta-estradiol-induced survivin expression and causes apoptotic cell death in endometrial cancer. Oncol. Lett. 2018, 16, 6195-6201.

231. Yang, T.O.; Crowe, F.; Cairns, B.J.; Reeves, G.K.; Beral, V. Tea and coffee and risk of endometrial cancer: Cohort study and meta-analysis. Am. J. Clin. Nutr. 2015, 101, 570-578. [CrossRef]

232. Zhou, Q.; Li, H.; Zhou, J.G.; Ma, Y.; Wu, T.; Ma, H. Green tea, black tea consumption and risk of endometrial cancer: A systematic review and meta-analysis. Arch. Gynecol. Obstet. 2016, 293, 143-155. [CrossRef] [PubMed]

233. Coburn, S.B.; Bray, F.; Sherman, M.E.; Trabert, B. International patterns and trends in ovarian cancer incidence, overall and by histologic subtype. Int. J. Cancer 2017, 140, 2451-2460. [CrossRef]

234. Jayson, G.C.; Kohn, E.C.; Kitchener, H.C.; Ledermann, J.A. Ovarian cancer. Lancet 2014, 384, 1376-1388. [CrossRef]

235. Goff, B.A.; Mandel, L.; Muntz, H.G.; Melancon, C.H. Ovarian carcinoma diagnosis. Cancer 2000, 89, 2068-2075. [CrossRef]

236. Kisielewski, R.; Mazurek, A.; Laudański, P.; Tołwińska, A. Inflammation and ovarian cancer-Current views. Ginekol. Pol. 2013, 84, 293-297. [CrossRef] [PubMed]

237. Shivappa, N.; Hébert, J.R.; Rosato, V.; Rossi, M.; Montella, M.; Serraino, D.; La Vecchia, C. Dietary inflammatory index and ovarian cancer risk in a large Italian case-control study. Cancer Causes Control 2016, 27, 897-906. [CrossRef]

238. Dolecek, T.A.; McCarthy, B.J.; Joslin, C.E.; Peterson, C.E.; Kim, S.; Freels, S.A.; Davis, F.G. Prediagnosis food patterns are associated with length of survival from epithelial ovarian cancer. J. Am. Diet. Assoc. 2010, 110, 369-382. [CrossRef]

239. Playdon, M.C.; Nagle, C.M.; Ibiebele, T.I.; Ferrucci, L.M.; Protani, M.M.; Carter, J.; Hyde, S.E.; Neesham, D.; Nicklin, J.L.; Mayne, S.T.; et al. Pre-diagnosis diet and survival after a diagnosis of ovarian cancer. Br. J. Cancer 2017, 116, 1627-1637. [CrossRef]

240. Qiu, W.; Lu, H.; Qi, Y.; Wang, X. Dietary fat intake and ovarian cancer risk: A meta-analysis of epidemiological studies. Oncotarget 2016, 7, 37390-37406. [CrossRef]

241. Bandera, E.V.; King, M.; Chandran, U.; Paddock, L.E.; Rodriguez-Rodriguez, L.; Olson, S.H. Phytoestrogen consumption from foods and supplements and epithelial ovarian cancer risk: A population-based case control study. BMC Wom. Health 2011, 11, 40. [CrossRef] [PubMed]

242. Neill, A.S.; Ibiebele, T.I.; Lahmann, P.H.; Hughes, M.C.; Nagle, C.M.; Webb, P.M. Dietary phyto-oestrogens and the risk of ovarian and endometrial cancers: Findings from two Australian case-control studies. Br. J. Nutr. 2014, 111, 1430-1440. [CrossRef] [PubMed]

243. Hedelin, M.; Löf, M.; Andersson, T.M.; Adlercreutz, H.; Weiderpass, E. Dietary phytoestrogens and the risk of ovarian cancer in the women's lifestyle and health cohort study. Cancer Epidemiol. Biomarkers Prev. 2011, 20, 308-317. [CrossRef] [PubMed]

244. Hua, X.; Yu, L.; You, R.; Yang, Y.; Liao, J.; Chen, D.; Yu, L. Association among Dietary flavonoids, flavonoid subclasses and ovarian cancer risk: A meta-analysis. PLoS ONE 2016, 11, e0151134. [CrossRef] [PubMed]

245. Shafabakhsh, R.; Asemi, Z. Quercetin: A natural compound for ovarian cancer treatment. J. Ovarian Res. 2019, 12, 55. [CrossRef]

246. Luo, H.; Rankin, G.O.; Liu, L.; Daddysman, M.K.; Jiang, B.H.; Chen, Y.C. Kaempferol inhibits angiogenesis and VEGF expression through both HIF dependent and independent pathways in human ovarian cancer cells. Nutr. Cancer 2009, 61, 554-563. [CrossRef]

247. Huang, H.; Chen, A.Y.; Ye, X.; Guan, R.; Rankin, G.O.; Chen, Y.C. Galangin, a flavonoid from lesser galangal, induced apoptosis via p53-dependent pathway in ovarian cancer cells. Molecules 2020, 25, 1579. [CrossRef]

248. Lin, Y.G.; Kunnumakkara, A.B.; Nair, A.; Merritt, W.M.; Han, L.Y.; Armaiz-Pena, G.N.; Kamat, A.A.; Spannuth, W.A.; Gershenson, D.M.; Lutgendorf, S.K.; et al. Curcumin inhibits tumor growth and angiogenesis in ovarian carcinoma by targeting the nuclear factor-kappaB pathway. Clin. Cancer Res. 2007, 13, 3423-3430. [CrossRef] [PubMed]

249. Pourhanifeh, M.H.; Darvish, M.; Tabatabaeian, J.; Fard, M.R.; Mottaghi, R.; Azadchehr, M.J.; Jahanshahi, M.; Sahebkar, A.; Mirzaei, H. Therapeutic role of curcumin and its novel formulations in gynecological cancers. J. Ovarian Res. 2020, 13, 30. [CrossRef] 
250. Wahl, H.; Tan, L.; Griffith, K.; Choi, M.; Liu, J.R. Curcumin enhances Apo2L/TRAIL-induced apoptosis in chemoresistant ovarian cancer cells. Gynecol. Oncol. 2007, 105, 104-112. [CrossRef] [PubMed]

251. He, M.; Wang, D.; Zou, D.; Wang, C.; Lopes-Bastos, B.; Jiang, W.G.; Chester, J.; Zhou, Q.; Cai, J. Re-purposing of curcumin as an anti-metastatic agent for the treatment of epithelial ovarian cancer: In vitro model using cancer stem cell enriched ovarian cancer spheroids. Oncotarget 2016, 7, 86374-86387. [CrossRef] [PubMed]

252. Yallapu, M.M.; Maher, D.M.; Sundram, V.; Bell, M.C.; Jaggi, M.; Chauhan, S.C. Curcumin induces chemo/radio-sensitization in ovarian cancer cells and curcumin nanoparticles inhibit ovarian cancer cell growth. J. Ovarian Res. 2010, 3, 11. [CrossRef]

253. Sun, Y.; Xun, K.; Wang, Y.; Chen, X. A systematic review of the anticancer properties of berberine, a natural product from Chinese herbs. Anticancer Drugs 2009, 20, 757-769. [CrossRef]

254. Liu, L.; Fan, J.; Ai, G.; Liu, J.; Luo, N.; Li, C.; Cheng, Z. Berberine in combination with cisplatin induces necroptosis and apoptosis in ovarian cancer cells. Biol. Res. 2019, 52, 37. [CrossRef] [PubMed]

255. Tse, A.K.; Wan, C.K.; Shen, X.L.; Yang, M.; Fong, W.F. Honokiol inhibits TNF-alpha-stimulated NF-kappaB activation and NF-kappaB-regulated gene expression through suppression of IKK activation. Biochem. Pharmacol. 2005, 70, 1443-1457. [CrossRef]

256. Lee, J.S.; Sul, J.Y.; Park, J.B.; Lee, M.S.; Cha, E.Y.; Ko, Y.B. Honokiol induces apoptosis and suppresses migration and invasion of ovarian carcinoma cells via AMPK/mTOR signaling pathway. Int. J. Mol. Med. 2019, 43, 1969-1978. [CrossRef] [PubMed]

257. Wu, S.H.; Wu, T.Y.; Hsiao, Y.T.; Lin, J.H.; Hsu, S.C.; Hsia, T.C.; Yang, S.T.; Hsu, W.H.; Chung, J.G. Bufalin induces cell death in human lung cancer cells through disruption of DNA damage response pathways. Am. J. Chin. Med. 2014, 42, 729-742. [CrossRef] [PubMed]

258. Su, S.; Dou, H.; Wang, Z.; Zhang, Q. Bufalin inhibits ovarian carcinoma via targeting mTOR/HIF-alpha pathway. Basic Clin. Pharmacol. Toxicol. 2020. [CrossRef]

259. Kosuge, T.; Adachi, T.; Kamiya, H. Isolation of tetramethylpyrazine from culture of Bacillus natto, and biosynthetic pathways of tetramethylpyrazine. Nature 1962, 195, 1103. [CrossRef] [PubMed]

260. Zhang, H.; Ding, S.; Xia, L. Ligustrazine inhibits the proliferation and migration of ovarian cancer cells via regulating miR-211. Biosci. Rep. 2020, 41, BSR20200199. [CrossRef] [PubMed]

261. Ciebiera, M.; Włodarczyk, M.; Ciebiera, M.; Zaręba, K.; Łukaszuk, K.; Jakiel, G. Vitamin D and Uterine Fibroids-Review of the Literature and Novel Concepts. Int. J. Mol. Sci. 2018, 19, 2051. [CrossRef]

262. Dovnik, A.; Dovnik, N.F. Vitamin D and ovarian cancer: Systematic review of the literature with a focus on molecular mechanisms. Cells 2020, 9, 335. [CrossRef]

263. Song, X.; Li, Z.; Ji, X.; Zhang, D. Calcium intake and the risk of ovarian cancer: A meta-analysis. Nutrients 2017, 9, 679. [CrossRef] [PubMed]

264. Livdans-Forret, A.B.; Harvey, P.J.; Larkin-Thier, S.M. Menorrhagia: A synopsis of management focusing on herbal and nutritional supplements, and chiropractic. J. Can. Chiropr. Assoc. 2007, 51, 235-246.

265. Geller, S.E.; Studee, L. Botanical and dietary supplements for menopausal symptoms: What works, what does not. J Wom. Health 2005, 14, 634-649. [CrossRef] [PubMed]

266. Low, M.S.; Speedy, J.; Styles, C.E.; De-Regil, L.M.; Pasricha, S.R. Daily iron supplementation for improving anaemia, iron status and health in menstruating women. Cochrane Datab. Syst. Rev. 2016, 4, CD009747. [CrossRef] [PubMed]

267. Lithgow, D.M.; Politzer, W.M. Vitamin A in the treatment of menorrhagia. S. Afr. Med. J. 1977, 51, 91-93.

268. Ayre, J.E.; Bauld, W.A. Thiamine deficiency and high. estrogen findings in uterine cancer and in menorrhagia. Science 1946, 103, 441-445. [CrossRef]

269. Cohen, J.D.; Rubin, H.W. Functional menorrhagia: Treatment with bioflavonoids and vitamin C. Curr. Ther. Res. Clin. Exp. 1960, 2, 539-542. [PubMed]

270. Morrow, C.; Naumburg, E.H. Dysmenorrhea. Prim. Care 2009, 36, 19-32. [CrossRef]

271. Dennehy, C.E. The use of herbs and dietary supplements in gynecology: An evidence-based review. J. Midwifery Women's Health 2006, 51, 402-409. [CrossRef]

272. Bajalan, Z.; Alimoradi, Z.; Moafi, F. Nutrition as a potential factor of primary dysmenorrhea: A systematic review of observational studies. Gynecol. Obstet. Invest. 2019, 84, 209-224. [CrossRef]

273. Pattanittum, P.; Kunyanone, N.; Brown, J.; Sangkomkamhang, U.S.; Barnes, J.; Seyfoddin, V.; Marjoribanks, J. Dietary supplements for dysmenorrhoea. Cochrane Database Syst. Rev. 2016, 3, CD002124. [CrossRef]

274. Naz, M.S.; Kiani, Z.; Fakari, F.R.; Ghasemi, V.; Abed, M.; Ozgoli, G. The effect of micronutrients on pain management of primary dysmenorrhea: A systematic review and meta-analysis. J. Caring Sci. 2020, 9, 47-56.

275. Shin, H.J.; Na, H.S.; Do, S.H. Magnesium and Pain. Nutrients 2020, 9, 2184. [CrossRef] [PubMed]

276. Chiang, Y.F.; Hung, H.C.; Chen, H.Y.; Huang, K.C.; Lin, P.H.; Chang, J.Y.; Huang, T.C.; Hsia, S.M. The inhibitory effect of extra virgin olive oil and its active compound oleocanthal on prostaglandin-induced uterine hypercontraction and pain-ex vivo and in vivo study. Nutrients 2020, 12, 3012. [CrossRef]

277. Lee, H.W.; Ang, L.; Lee, M.S.; Alimoradi, Z.; Kim, E. Fennel for reducing pain in primary dysmenorrhea: A systematic review and meta-analysis of randomized controlled trials. Nutrients 2020, 12, 3438. [CrossRef] [PubMed]

278. Nagata, C.; Hirokawa, K.; Shimizu, N.; Shimizu, H. Associations of menstrual pain with intakes of soy, fat and dietary fiber in Japanese women. Eur. J. Clin. Nutr. 2005, 59, 88-92. [CrossRef] 
279. Mehrpooya, M.; Eshraghi, A.; Rabiee, S.; Larki-Harchegani, A.; Ataei, S. Comparison the effect of fish-oil and calcium supplementation on treatment of primary dysmenorrhea. Rev. Recent Clin. Trials 2017, 12, 148-153. [CrossRef]

280. Sadeghi, N.; Paknezhad, F.; Rashidi Nooshabadi, M.; Kavianpour, M.; Jafari Rad, S.; Khadem Haghighian, H. Vitamin E and fish oil, separately or in combination, on treatment of primary dysmenorrhea: A double-blind, randomized clinical trial. Gynecol. Endocrinol. 2018, 34, 804-808. [CrossRef]

281. Lerchbaum, E.; Rabe, T. Vitamin D and female fertility. Curr. Opin. Obstet. Gynecol. 2014, 26, 145-150. [CrossRef] [PubMed]

282. Bahrami, A.; Avan, A.; Sadeghnia, H.R.; Esmaeili, H.; Tayefi, M.; Ghasemi, F.; Nejati Salehkhani, F.; Arabpour-Dahoue, M.; Rastgar-Moghadam, A.; Ferns, G.A.; et al. High. dose vitamin D supplementation can improve menstrual problems, dysmenorrhea, and premenstrual syndrome in adolescents. Gynecol. Endocrinol. 2018, 34, 659-663. [CrossRef]

283. Abdi, F.; Amjadi, M.A.; Zaheri, F.; Rahnemaei, F.A. Role of vitamin D and calcium in the relief of primary dysmenorrhea: A systematic review. Obstet. Gynecol. Sci. 2021, 64, 13-26. [CrossRef] [PubMed]

284. Zhang, Y.; Mao, X.; Su, J.; Geng, Y.; Guo, R.; Tang, S.; Li, J.; Xiao, X.; Xu, H.; Yang, H. A network pharmacology-based strategy deciphers the underlying molecular mechanisms of Qixuehe Capsule in the treatment of menstrual disorders. Chin. Med. 2017, 12, 23. [CrossRef] [PubMed]

285. Zekavat, O.R.; Karimi, M.Y.; Amanat, A.; Alipour, F. A randomised controlled trial of oral zinc sulphate for primary dysmenorrhoea in adolescent females. Aust. N. Z. J. Obstet. Gynaecol. 2015, 55, 369-373. [CrossRef]

286. Nasiadek, M.; Stragierowicz, J.; Klimczak, M.; Kilanowicz, A. The role of zinc in selected female reproductive system disorders. Nutrients 2020, 12, 2464. [CrossRef] [PubMed]

287. Chao, M.T.; Wade, C.M.; Booth, S.L. Increase in plasma phylloquinone concentrations following acupoint injection for the treatment of primary dysmenorrhea. J. Acupunct. Meridian. Stud. 2014, 7, 151-154. [CrossRef]

288. Wade, C.; Wang, L.; Zhao, W.J.; Cardini, F.; Kronenberg, F.; Gui, S.Q.; Ying, Z.; Zhao, N.Q.; Chao, M.T.; Yu, J. Acupuncture point injection treatment of primary dysmenorrhoea: A randomised, double blind, controlled study. BMJ Open 2016, 6, e008166. [CrossRef]

289. Fujiwara, T.; Ono, M.; Mieda, M.; Yoshikawa, H.; Nakata, R.; Daikoku, T.; Sekizuka-Kagami, N.; Maida, Y.; Ando, H.; Fujiwara, H. Adolescent dietary habit-induced obstetric and gynecologic disease (ADHOGD) as a new hypothesis-possible involvement of clock system. Nutrients 2020, 12, 1294. [CrossRef] 